OPEN ACCESS

Edited by:

Shawn Hayley,

Carleton University, Canada

Reviewed by:

Giamal Luheshi,

McGill University, Canada

Björn Spittau,

Albert Ludwig University of Freiburg,

Germany

${ }^{*}$ Correspondence:

Duraisamy Kempuraj duraisamyk@health.missouri.edu

Asgar Zaheer

zaheera@health.missouri.edu

Received: 09 April 2017 Accepted: 05 July 2017

Published: 24 July 2017

Citation:

Kempuraj $D$, Thangavel $R$,

Selvakumar GP, Zaheer $S$, Ahmed ME, Raikwar SP, Zahoor H,

Saeed D, Natteru PA, Iyer S and Zaheer A (2017) Brain and Peripheral

Atypical Inflammatory Mediators

Potentiate Neuroinflammation and

Neurodegeneration.

Front. Cell. Neurosci. 11:216.

doi: 10.3389/fncel.2017.00216

\section{Brain and Peripheral Atypical Inflammatory Mediators Potentiate Neuroinflammation and Neurodegeneration}

\author{
Duraisamy Kempuraj ${ }^{1,2 *}$, Ramasamy Thangavel ${ }^{1,2}$, Govindhasamy P. Selvakumar ${ }^{1,2}$, \\ Smita Zaheer ${ }^{2}$, Mohammad E. Ahmed ${ }^{2}$, Sudhanshu P. Raikwar ${ }^{1,2}$, Haris Zahoor ${ }^{2}$, \\ Daniyal Saeed ${ }^{2}$, Prashant A. Natteru ${ }^{2}$, Shankar lyer ${ }^{1,2}$ and Asgar Zaheer ${ }^{1,2 *}$

\begin{abstract}
'Harry S. Truman Memorial Veteran's Hospital, U.S. Department of Veterans Affairs, Columbia, MO, United States, ${ }^{2}$ Department of Neurology and the Center for Translational Neuroscience, School of Medicine, University of Missouri, Columbia, MO, United States
\end{abstract}

Neuroinflammatory response is primarily a protective mechanism in the brain. However, excessive and chronic inflammatory responses can lead to deleterious effects involving immune cells, brain cells and signaling molecules. Neuroinflammation induces and accelerates pathogenesis of Parkinson's disease (PD), Alzheimer's disease (AD) and Multiple sclerosis (MS). Neuroinflammatory pathways are indicated as novel therapeutic targets for these diseases. Mast cells are immune cells of hematopoietic origin that regulate inflammation and upon activation release many proinflammatory mediators in systemic and central nervous system (CNS) inflammatory conditions. In addition, inflammatory mediators released from activated glial cells induce neurodegeneration in the brain. Systemic inflammation-derived proinflammatory cytokines/chemokines and other factors cause a breach in the blood brain-barrier (BBB) thereby allowing for the entry of immune/inflammatory cells including mast cell progenitors, mast cells and proinflammatory cytokines and chemokines into the brain. These peripheral-derived factors and intrinsically generated cytokines/chemokines, $\alpha$-synuclein, corticotropinreleasing hormone $(\mathrm{CRH})$, substance $\mathrm{P}(\mathrm{SP})$, beta amyloid 1-42 (A $\beta 1-42)$ peptide and amyloid precursor proteins can activate glial cells, T-cells and mast cells in the brain can induce additional release of inflammatory and neurotoxic molecules contributing to chronic neuroinflammation and neuronal death. The glia maturation factor (GMF), a proinflammatory protein discovered in our laboratory released from glia, activates mast cells to release inflammatory cytokines and chemokines. Chronic increase in the proinflammatory mediators induces neurotoxic $A \beta$ and plaque formation in $A D$ brains and neurodegeneration in PD brains. Glial cells, mast cells and T-cells can reactivate each other in neuroinflammatory conditions in the brain and augment neuroinflammation. Further, inflammatory mediators from the brain can also enter into the peripheral system through defective BBB, recruit immune cells into the brain, and exacerbate neuroinflammation. We suggest that mast cell-associated inflammatory mediators from systemic inflammation and brain could augment neuroinflammation and neurodegeneration in the brain. This review article addresses the role of some atypical 
inflammatory mediators that are associated with mast cell inflammation and their activation of glial cells to induce neurodegeneration.

Keywords: brain, cytokines and chemokines, mast cells, inflammatory mediators, neuroinflammation, neurodegenerative diseases

\section{INTRODUCTION}

Neuroinflammation is an inherent host-defense mechanism to protect and restore the normal structure and function of the brain against infection and injury (More et al., 2013). In neurodegenerative diseases, neuroinflammation initially clears up infection to control the disease severity and progression. However, neuroinflammation also acts as a double-edged sword (Kielian, 2016). On the one side, neuroinflammation induces and/or aggravates neurodegeneration in the central nervous system (CNS), while on the other side, it favors the recovery of the injured neurons (Lucas et al., 2006). A recent study indicates that neuroinflammation promotes regeneration to some extent (Bollaerts et al., 2017). Chronic inflammation induces cytotoxic effects and increases the severity of neurodegenerative disease symptoms. Neuroinflammation is the leading cause of devastating neurodegenerative diseases such as Parkinson's disease (PD), Alzheimer's disease (AD), Amyotrophic lateral sclerosis (ALS) and Multiple sclerosis (MS)/Experimental autoimmune encephalomyelitis (Chen et al., 2016; Kempuraj et al., 2016b). The activated glial cells release several pro-inflammatory cytokines, chemokines and reactive oxygen species (ROS), which mediate neuroinflammationinduced neurodegenerative disease mechanisms (Kempuraj et al., 2016b). Anti-inflammatory cytokines synthesized by regulatory $\mathrm{T}$ cells and neuropeptides secreted by neurons and other cells protect the neurons against neuroinflammation, which helps alleviate the symptoms of neurodegenerative diseases. Recent evidence supports that neuroinflammatory processes involving immune cells, glial cells and neuronal cells are very crucial and fundamental to understanding the origin or pathogenesis of a disease, such as a progressive loss of dopaminergic neurons in PD (Chung et al., 2010; More et al., 2013; Kong et al., 2017; Visan, 2017). Additionally, peripheral inflammation also increases brain inflammatory responses through several mechanisms (Machado et al., 2011; Hernández-Romero et al., 2012; Takeda et al., 2013). Previous studies have shown that non-steroidal anti-inflammatory drugs (NSAIDs), statins and other drugs provide some relief although they are ineffective for neurodegenerative diseases (Szekely and Zandi, 2010; Lehrer, 2014; Kure et al., 2017). This is because the NSAIDs do not efficiently cross the blood brain-barrier (BBB) and do not attain therapeutic levels that are necessary to overcome and reverse neuroinflammation. Therefore, therapeutic options like nasal NSAIDs have been suggested to improve its bioavailability and effectiveness in neuroinflammation by increasing the concentration in the brain (Lehrer, 2014).

The existence of bidirectional communication between the brain and the peripheral immune system has been known over the past two decades (Johnson et al., 1997; Dantzer et al., 2000; Holmes and Butchart, 2011; Hernández-Romero et al., 2012; McCusker and Kelley, 2013; Träger and Tabrizi, 2013; Engelhardt et al., 2017). Neuroinflammation is known to directly and systemically contribute to the recruitment of peripheral inflammatory cells and increase BBB permeability in the neurodegenerative diseases (Hayley and Anisman, 2005; Ferrari and Tarelli, 2011; Espinosa-Oliva et al., 2014; Dendrou et al., 2016; McManus and Heneka, 2017; Schain and Kreisl, 2017). Peripheral infection and inflammation increases $\mathrm{BBB}$ permeability and neuroinflammation in the animal model of AD (Takeda et al., 2013). Systemic inflammation also affects hippocampus-dependent memory (Culley et al., 2014; Takeda et al., 2014). Microglia, the macrophage of the brain, is an important resident innate immune cell in the brain. Activation of microglia induces their proliferation in neuroinflammatory conditions (Perry et al., 2010; Perry, 2016). Additionally, astrocytes, neurons, brain pericytes, $\mathrm{T}$ cells and mast cells also play a significant role in the brain inflammatory mechanisms. Inflammatory mediators, neurotoxic mediators, inflammasomes and hormones released by the activated glial cells and injured neurons are involved in neuroinflammation in $\mathrm{AD}$ and $\mathrm{PD}$ pathogenesis (Tufekci et al., 2012; Pennisi et al., 2016; Becher et al., 2017; Gualtierotti et al., 2017; Rustenhoven et al., 2017; Sawikr et al., 2017; Song et al., 2017). Substantia nigra has the highest density of microglial cells, which are found, to be activated in $\mathrm{PD}$ brains. In $\mathrm{AD}$, activated microglial cells are found surrounding the beta-amyloid $(\mathrm{A} \beta)$ plaques. Microglial activation and inhibition of microglial activation is tightly regulated by a number of microRNAs including pro-inflammatory mir-155 and mir-204 as well as anti-inflammatory mir-203, mir-181c and mir-424 (Cardoso et al., 2012; Li L. et al., 2015). More recently, using the 1-methyl4-phenyl-1,2,3,6-tetrahydropyridine (MPTP) mouse PD model, a study has shown that 1-methyl-4-phenylpyridinium $\left(\mathrm{MPP}^{+}\right)$ downregulates mir-7116-5p in microglia and potentiates TNF- $\alpha$ production and inflammatory responses leading to DA neuron damage (He et al., 2017).

In addition to significant brain innate immune system activation, peripheral innate immune system activation is recognized as a prominent feature contributing to the severity of neuroinflammatory diseases progression (Träger and Tabrizi, 2013). Systemic inflammation exacerbates clinical symptoms, neuroinflammation and neuronal death in older people and in patients who have suffered stroke and chronic neurodegenerative disease (Teeling and Perry, 2009). Systemic infection and increased IL-1 $\beta$ have been reported to induce a cognitive decline in $\mathrm{AD}$ patients (Holmes et al., 2003). Systemic inflammation could induce behavioral and 
cognitive changes and accelerate neurodegenerative disease pathogenesis (Perry, 2004; Perry et al., 2007; Cunningham et al., 2009). Excess accumulation of activated immune cells in the brain has been well documented in studies covering multiple neurodegenerative diseases. Inflammatory mediator levels in the plasma are elevated in neuroinflammatory conditions. Thus, cytokine levels can be used as a biomarker for neuroinflammatory diseases including PD (Litteljohn and Hayley, 2012). Cytokine and chemokine levels correlate between cerebrospinal fluid (CSF) and plasma in $\mathrm{AD}$ (Sun et al., 2003) and PD (Blum-Degen et al., 1995). This indicates that similar type of immune responses occur in the brain and periphery, and show the communication between the brain and peripheral immune systems. An interesting study demonstrated upregulation of nuclear factor-kappaB (NF-кB) activation in the peripheral blood mononuclear cells in $\mathrm{AD}$ patients thereby suggesting NF- $\mathrm{KB}$ inhibitors as therapeutic agents in AD patients (Ascolani et al., 2012). Imbalance of peripheral $\mathrm{T}$ cell subsets (decreased $\mathrm{CD}^{+}$and increased $\mathrm{CD}^{+}$cells) has been reported in $\mathrm{AD}$ patients indicating peripheral immune response in AD (Shalit et al., 1995); this is similar to a previous report on brain tumor patients that showed altered peripheral immune parameters in patients with a brain tumor (Kempuraj et al., 2004a). Increased TNF- $\alpha$ levels due to either acute or chronic systemic inflammation have been shown to increase cognitive decline in $\mathrm{AD}$ (Holmes et al., 2009) and neurodegeneration in PD (Litteljohn et al., 2010). A previous study has shown that systemic injection of TNF- $\alpha$ into an adult mouse activates brain microglia to produce proinflammatory mediators that induces death of dopaminergic neurons in the substantia nigra (Qin et al., 2007), and this demonstrates a direct link between systemic inflammatory factors and neurodegeneration in the brain. Moreover, during sustained immune response in the brain, several multifunctional pro inflammatory factors, mast cells and $\mathrm{T}$ cells from the periphery migrate to the brain, and go directly to or through glial cells while neurons augment and maintain chronic neuroinflammatory responses leading to neurodegeneration (Prinz and Priller, 2017). However, the communication between peripheral inflammatory factors, brain inflammatory factors and the cells in neuroinflammation is not yet clearly understood. Thus, no effective treatment options are currently available for neurodegenerative diseases. Multiple studies have demonstrated that systemic inflammation induces onset and progression of neuroinflammation and neurodegeneration in the CNS. Mast cells play an important role in the systemic inflammation by releasing various inflammatory, neuroactive and vasoactive mediators. Several previous review articles have shown how inflammatory mediators such as IL-1, TNF- $\alpha$, IL- 6 , chemokine (C-C motif) ligand 2 (CCL2), ROS released by microglia, T-cells and mast cells induce neuroinflammation. Although mast cells release many neuroinflammatory mediators, we will focus only on select atypical mediators in this review article. This review article will focus on the mast cell associated peripheral and brain inflammatory mediators and mast cells that migrate into the brain and either directly or through astrocytes, microglia and neurons induce and sustain neuroinflammation leading to neuronal death.

\section{MAST CELLS IN NEUROINFLAMMATION}

Mast cells are crucial in allergic and anaphylactic reactions, acquired and innate immunity, tissue damage and repair processes, and pain mechanisms (Schwartz, 2002; Metz et al., 2007; Galli et al., 2008; Gilfillan et al., 2011; Tete et al., 2012; Saito, 2014; Morita et al., 2016). Mast cells develop from hematopoietic progenitor cells in the bone marrow, move to various tissues and mature into different types of mast cells (Gurish and Austen, 2001). Mast cells are implicated in several allergic and inflammatory diseases including neurodegenerative and demyelinating diseases (Brown and Hatfield, 2012; Conti and Kempuraj, 2016; Russi et al., 2016; Theoharides et al., 2016; Li et al., 2017; Yehya and Torbey, 2017). Mast cells are involved in both peripheral inflammatory conditions and diseases including allergies, asthma, cancer, arthritis, psoriasis, interstitial cystitis, rhinitis, MS, PD, stroke, increased BBB permeability, autism, pain, migraines, sleep disorders, intracerebral hemorrhage, stress and inflammation as shown in Figure 1. The systemic inflammatory conditions and diseases can exacerbate neuroinflammation through several different pathways. Mast cells are multifunctional sensor and effector cells in nervous, vascular and immune system disorders (Ryan et al., 2009; Silver et al., 2010). In the brain, mast cells are primarily located on the brain side of the BBB, and communicate with neurons, glia and neurovascular components by releasing their mediators and through mast cell receptors (Silver and Curley, 2013; Dong et al., 2014). Mast cells are generally seen near the glial cells in neuroinflammatory conditions, indicating their interactions with brain cells in neuroinflammation. Various factors such as species, sex, age and outside environmental conditions controls the number and the extent of its activation in the brain (Silver and Curley, 2013). Additionally, the number of mast cells also vary based upon staining and other detection techniques used. In a physiological condition, the total number of mast cells present in the CNS is limited. But, mast cells are very powerful cells and even a few mast cells can release sufficient quantity of inflammatory mediators that can affect BBB and activate glia and neurons in the CNS (Silver and Curley, 2013). Mast cells release neurotrophic factors such as nerve growth factor (NGF) and facilitate neurotransmission, neuronal growth and survival in the normal brain (Kritas et al., 2014a). However, increased number of mast cell involvement and their activation is deleterious, since this could increase BBB permeability, activate astrocytes, oligodendrocytes, microglia and $\mathrm{T}$ cells in neuroinflammation (Zhang et al., 2016). Mast cells are resident in the CNS (Skaper et al., 2014), and also able to cross BBB into the brain from the peripheral tissue in neuroinflammatory conditions (Skaper et al., 2012) as well as in physiological conditions (Silverman et al., 2000). Mast cells can recruit and activate other inflammatory cells and glial cells in the brain at the site of inflammation and induce vasodilation in neuroinflammation as 


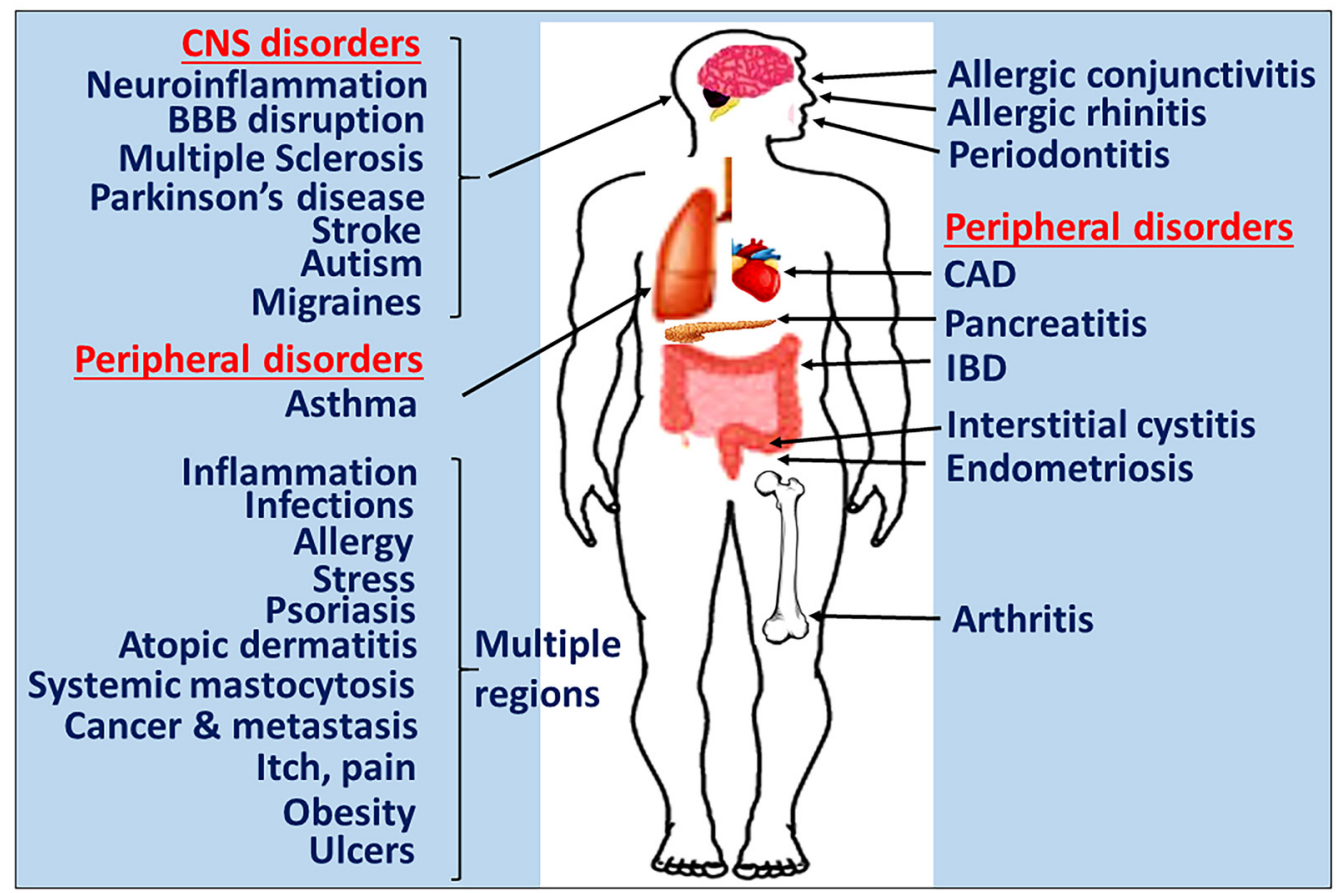

FIGURE 1 | Mast cells in inflammatory diseases. Mast cells play a crucial role in the pathogenesis of many inflammatory diseases of various organs. Certain systemic inflammatory conditions could affect and augment neuroinflammation and neurodegeneration. Therefore, targeting mast cells represents a potentially novel approach to developing the next generation of precision guided therapeutic strategies for the treatment of inflammatory diseases. IBD, inflammatory bowel disease; CAD, coronary artery disease; BBB, blood-brain barrier.

shown in Figure 2 (Nelissen et al., 2013; Yehya and Torbey, 2017).

Mast cells release multifunctional cytokines/chemokines and neuroactive mediators including IL-1 $\beta$, IL-6, IL-8, IL-18, IL-33, TNF- $\alpha$, vascular endothelial growth factor (VEGF), corticotropin-releasing hormone (CRH), granulocyte macrophage-colony stimulating factor (GM-CSF), CCL2, dopamine, substance $\mathrm{P}$ (SP), histamine, tryptase, prostaglandins (PGD), leukotrienes, ROS, reactive nitrogen species (RNS) and nitric oxide (NO) selectively depending upon the tissue micro environment and the type of stimuli (Mekori and Metcalfe, 2000; Kalesnikoff and Galli, 2008; Sismanopoulos et al., 2012; Theoharides et al., 2012; Kempuraj et al., 2013). Cytokines such as IL- $1 \beta$ and TNF- $\alpha$ in higher concentrations either directly induce neuronal damage or through activating glial cells, and these cytokines are suggested as a drug target in brain injury therapy (Allan and Rothwell, 2001, 2003; Allan et al., 2005; Brough et al., 2015).

We were the first to show that IL-1 can activate mast cells to release inflammatory mediators (Kandere-Grzybowska et al., 2003). Mast cell-derived vasoactive and inflammatory mediators cause vasoconstriction, increased vascular permeability, edema and inflammatory cell recruitment to the site of inflammation. Mast cells are implicated in all stages of inflammation, tissue damage, and tissue repair mechanisms after the inflammatory responses are over in the inflamed tissues (Kim et al., 2011; Skaper et al., 2012, 2013; Zhang et al., 2012). Mast cells are important sensors of cell injury and damage through IL-33 recognition after it is released from the injured cells (Enoksson et al., 2011). Microglia, the resident brain immune cells and mast cells are considered as two important cells that can mediate neuroinflammation in the brain. Moreover, mast cells can respond and release many neuropeptides that are implicated in the process of neuroinflammation (Tore and Tuncel, 2009; Skaper et al., 2012). Mast cells cross-talk with T-cells, astrocytes, oligodendrocytes and microglia during the pathogenesis of chronic neurodegenerative diseases (Skaper and Facci, 2012; Skaper et al., 2012, 2014; Skaper, 2016). Mast cells can communicate with microglia, astrocytes and neurons through CD40L, CD40, toll-like receptor 2 (TLR2), TLR4, proteaseactivated receptor 2 (PAR2), CXCR4/C-X-C motif chemokine 12 (CXCL12) and C5aR (CD88). Mast cells also influence glia migration and activation associated with inflammatory mediator release (Kim et al., 2011; Skaper et al., 2012, 2013; Zhang et al., 2012).

Mast cells are the major link between neurons and neuroinflammation (Tore and Tuncel, 2009). Furthermore, mast cells and microglia are known to trigger the activation of two different signaling pathways in neuroinflammation (Skaper et al., 2012; Kempuraj et al., 2016b). Mast cells communicate with neurovascular unit components and induce cognitive dysfunction (Li et al., 2017). Our recent report stating that mast cells are activated by the proinflammatory brain protein glia maturation factor (GMF), strengthens the link between mast cells 


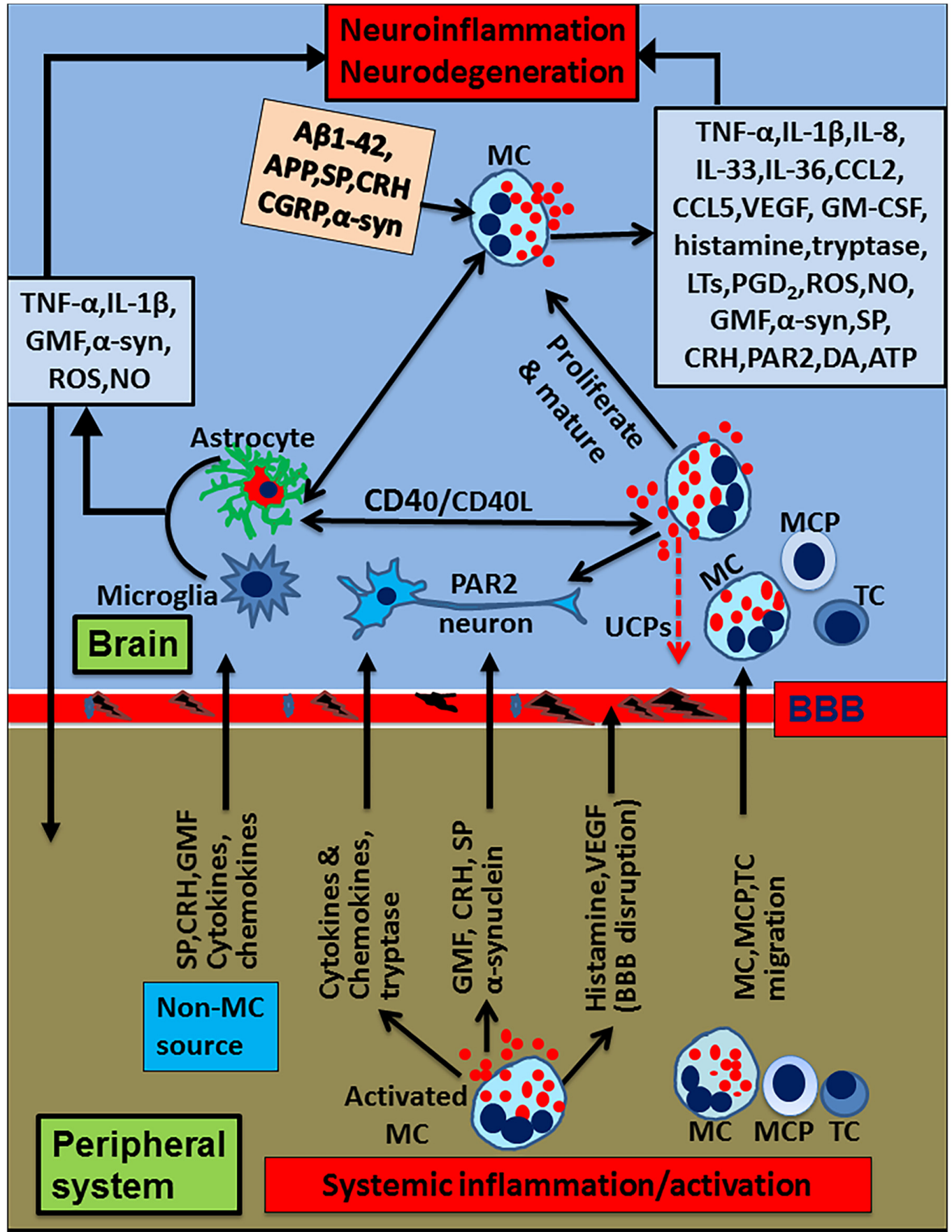

FIGURE 2 | Schematic diagram showing peripheral inflammatory factors and cells on neuroinflammation and neurodegeneration. Peripheral mast cell activation releases proinflammatory and neurotoxic mediators such as histamine, glia maturation factor (GMF), $\alpha$-synuclein, corticotropin-releasing hormone (CRH), proteases, cytokines and chemokines. These mediators can induce neuroinflammation by inducing BBB breakdown, entering into the brain and activating glia and neurons to secrete various additional inflammatory mediators. Peripheral mast cells and T-cells enter into the brain, proliferate and secrete proinflammatory mediators that activate glia and neurons to secrete more inflammatory mediators, reduce uncoupling protein (UCP) expression, and induce neurodegeneration. Further, glia and mast cells reactivate each other in the brain through co-stimulatory molecules CD40/CD154 or inflammatory mediators such as TNF- $\alpha$, IL-1 $\beta$ or IL-33. Mast cell tryptase acts on the neurons through PAR2. Mast cells can reactivate by their own mediators in an autocrine and paracrine manner to exacerbate inflammatory mechanisms. $\alpha$-synuclein or MPP+ from glia/neuron or extracellular A 1-42 can further activate mast cells to release neuroinflammatory mediators in Alzheimer's disease (AD) or Parkinson's disease (PD). Additionally several inflammatory mediators from the peripheral system can alter BBB, enter the brain and activate the neuroinflammatory pathways. Inflammatory mediators released from activated microglia and astrocytes can enter into peripheral system through defective BBB; then, they can activate and recruit immune and inflammatory cells towards the inflammatory site in the brain. MC, mast cell; MCP, mast cell progenitor; TC, T-cell; PAR2, protease activated receptor-2. 
and brain cells in neuroinflammation (Kempuraj et al., 2016a). Astrocytes also express receptors for mast cells histamine in addition to other receptors indicating the interaction between these cells (Hösli et al., 1984). Mast cell degranulation-derived proteases cleave tryptase-activated receptors (PARs) expressed on the neurons in neuroinflammation and neurodegeneration (Saito and Bunnett, 2005). Mast cell granules also contain dopamine that is released upon activation (Freeman et al., 2001). Previous reports demonstrated that mast cell activation induces and promotes the severity of EAE and that mast cell deficient mice show reduced EAE disease severity. Mast cell reconstitutions into mast cell-deficient mice have been used to study the role of mast cells in CNS diseases (Secor et al., 2000; Sayed et al., 2011). Reconstitution of mast cell deficient mice with cultured mouse bone marrow-derived mast cells (BMMCs) generally restores mast cells in the CNS (Johnson et al., 1991). Mast cells could also act outside the CNS to influence its effects inside the CNS as demonstrated in EAE models (Tanzola et al., 2003). Previous study has shown that mast cell reconstitution in mast cell-deficient mice restores conditions similar to wild type mice (Enoksson et al., 2011). Mast cells can communicate with neurons through the cell adhesion molecule-1 (CADM), $\mathrm{N}$-cadherin, and through the transgranulation process (Wilhelm et al., 2005; Héron and Dubayle, 2013). Activated mast cells induce BBB permeability by releasing vasoactive molecules such as histamine, proteases and metalloproteinases (Héron and Dubayle, 2013). Mast cell-derived histamine affects sleepwakefulness and other basic behavioral functions (Chikahisa et al., 2013). The types and strength of activation signals as well as mast cell phenotype determine the extent of mast cell activation in inflammatory conditions. Mast cell activation leads to acute explosive degranulation (rapid process) with inflammatory mediators released into extracellular spaces, and also by the selective release of cytokines and chemokines (slow process) (Nelissen et al., 2013). Mast cell-derived mediators that could disrupt BBB include CRH, histamine, VEGF, IL-8, TNF- $\alpha$, tryptase, prostaglandin D2 $\left(\mathrm{PGD}_{2}\right), \mathrm{SP}$, bradykinin, endorphin, endothelin, neurotensin, NO, vasoactive intestinal polypeptide (VIP) and urocortin (Abbott, 2000; Theoharides and Konstantinidou, 2007; Theoharides et al., 2008; Gu et al., 2015).

$\mathrm{A} \beta 1-42$ is the major component of amyloid plaques (APs) in an $\mathrm{AD}$ brain. $\mathrm{A} \beta 1-42$ is known to activate mast cells that could play an important role in AD pathogenesis (Niederhoffer et al., 2009). In fact the presence of $A \beta$ and tau-protein was detected in the mast cells of peripheral organs such as the skin and stomach of patients with AD (Kvetnoi et al., 2003). Dopaminergic neuronal injury may be detected by mast cells since these cells can detect cellular injury through the IL-33 recognition mechanism (Enoksson et al., 2011). We suggest that in addition to the well-known glial cells activation, mast cells activation with subsequent release of proinflammatory cytokines and chemokines from mast cells as well as mast cell-mediated enhanced proinflammatory mediators from the glia could exacerbate neuroinflammatory conditions leading to neurodegeneration in $\mathrm{PD}$ and $\mathrm{AD}$. Our recent findings suggest that activation of mast cells by GMF, $\mathrm{MPP}^{+}$and $\alpha$-synuclein and release of cytokines, chemokines and neurotoxic molecules and the expression of GMF by mast cells indicate new drug targets for PD and other neuroinflammatory conditions (Kempuraj et al., 2015, 2016a). This review article mainly deals with mast cell association with mitochondrial uncoupling proteins (UCPs), $\alpha$-synuclein, GMF, CRH, SP and dopamine in neuroinflammatory conditions.

\section{MITOCHONDRIAL UNCOUPLING PROTEIN (UCP) IN NEUROINFLAMMATION}

UCP2 and UCP4, members of the UCP family are neuroprotective by reducing the formation of ROS and are implicated in neurodegeneration and brain injury (Normoyle et al., 2015), AD (Wu et al., 2010) and PD (Andrews et al., 2005; Ho et al., 2012; Peixoto et al., 2013). UCPs reside on the inner mitochondrial membrane where they alter the mitochondrial membrane potential and ROS production and protect neurons (Cardoso et al., 2015). UCP2 and UCP4 regulate intracellular calcium levels and neurotransmission in the neurons. Abnormal expression of UCP2 and UCP4 has been reported in AD (Wu et al., 2009, 2010). Overexpression or activation of UCP2 and UCP4 may be a new strategy for reducing allergic and inflammatory responses since overexpression protects neurons after $\mathrm{MPP}^{+}$and dopamine-induced toxicity (Ho et al., 2012). UCP4 is primarily expressed in the brain (Ramsden et al., 2012). UCP4 is neuroprotective and important in energy homeostasis and is decreased in PD mice model. Overexpression of UCP4 reduced oxidative stress and inhibited apoptosis (Ho et al., 2012; Ramsden et al., 2012). The expression of UCP2 was demonstrated in lymphocytes, dendritic cells, neutrophils and macrophages (Rousset et al., 2006). UCP2 ${ }^{-/-}$mice develop more severe EAE (Aheng et al., 2011). Macrophages from UCP2 ${ }^{-/-}$ mice have a greater inflammatory response to lipopolysaccharide (LPS), including increased NF- $\mathrm{kB}$ activation and greater cytokine production. Macrophages overexpressing UCP2 produce less ROS in response to LPS (Negre-Salvayre et al., 1997) and have decreased transendothelial migration (Ryu et al., 2004). Both mitochondrial and cytosolic ROS are also produced by mast cells. Inhibition of ROS production reduces mast cell degranulation, indicating that ROS may play a role in regulating exocytosis process.

Recent studies have suggested that UCP2 manipulation could drive microglia towards protective phenotypes (De Simone et al., 2015). UCP2 activity inhibits exocytosis of dopaminecontaining vesicles from rat PC12 cells. UCP2 also dampens the inflammatory response of macrophages. We have previously reported the expression of UCP2 by mouse mast cells, and the LAD 2 human mast cell line, and recently showed the expression of UCP4 by mouse mast cells using immunohistochemical staining (Tagen et al., 2009; Kempuraj et al., 2016a). UCP ${ }^{-/-}$ mouse BMMCs have greater release of proinflammatory molecules after both allergic and non-allergic triggers, in addition to having increased histamine content and increased skin vascular permeability (Tagen et al., 2009). Activated BMMCs from UCP2 ${ }^{-/-}$mice have exhibited greater histamine release, whereas overexpression of UCP2 in LAD2 mast cells 
have reduced histamine release. $\mathrm{UCP}^{-/-}$BMMCs have also had elevated histamine content and histidine decarboxylase expression (Tagen et al., 2009). UCP2 ${ }^{-/-}$BMMCs have also had greater production of both IL-6 and $\mathrm{PGD}_{2}$, as well as extracellular signal-regulated kinase (ERK) phosphorylation, which is known to regulate prostaglandin synthesis (Tagen et al., 2009). UCP2 can regulate mast cell activation in neuroinflammatory conditions. These studies indicate that UCP2 is a novel regulator of mast cell function with a potential for treatment of mast cell-mediated allergic and inflammatory diseases including neurodegenerative and autoimmune diseases (Tagen et al., 2009; Ho et al., 2012). We have recently shown a downregulation of expression of both UCP2 and UCP4 in the parahippocampal gyrus of $\mathrm{AD}$ brains (Thangavel et al., 2017). All these reports show that UCPs expression dynamics in mast cells in the peripheral tissue as well as in the CNS could influence the neuroprotective state. Therefore, it would be worthwhile to examine the molecular mechanism/s underlying transcriptional and posttranscriptional regulation of UCP2 and UCP4. Especially, it would be interesting to decipher the potential role of microRNAs in downregulating the expression of UCP2 and UCP4, not only in AD, but also in $\mathrm{PD}$ and other neurodegenerative diseases. Furthermore, targeted overexpression of UCP2 and UCP4 in neurodegenerative diseases could potentially establish their therapeutic as well as neuroprotective effects.

\section{$\alpha$-SYNUCLEIN IN NEUROINFLAMMATION}

$\alpha$-synuclein is a cytosolic protein expressed in many immune cells and forms Lewy bodies in the PD brain. $\alpha$-synuclein is the major component in Lewy bodies and it has been identified as a possible biomarker for PD (Si et al., 2017). $\alpha$-synuclein is produced by cells in the peripheral tissues as well as from the CNS cells; it is also reported in the blood along with CSF (Sui et al., 2014). $\alpha$-synuclein is present in the neurons and glia of substantia nigra, thalamus, neocortex and hippocampus. $\alpha$-synuclein is implicated in both physiological and pathological functions. This cytosolic protein plays an important role in the pathogenesis of PD by inducing neuronal death in the substantia nigra. Extracellular $\alpha$-synuclein can induce neuroinflammatory reactions in glial cells leading to neurodegeneration. Radiolabeled $\alpha$-synuclein has been demonstrated to move across $\mathrm{BBB}$ in both directions and this movement could have important therapeutic significance (Sui et al., 2014). High levels of $\alpha$-synuclein in blood could contribute to CNS pathology, since the plasma levels of $\alpha$-synuclein are significantly higher than in the CSF levels (Shi et al., 2014). $\alpha$-synuclein from neurons enter into the glial cells and induce the secretion of proinflammatory cytokines and chemokines; moreover, this release is directly proportional to the amount of $\alpha$-synuclein in the glial cells (Lee et al., 2010). Recently, a neuronto-neuron transfer of $\alpha$-synuclein aggregates has been reported in the cell culture system as well as in transgenic mice with neuronal progenitor cell grafts (Desplats et al., 2009). The transferred $\alpha$-synuclein induces Lewy bodies-like inclusion and apoptotic changes in the recipient neurons. Thus, neuronal-derived excess $\alpha$-synuclein is transferred and accumulates in the neurons and glia, inducing pathological inclusion formation and degenerative changes. An increased level of $\alpha$-synuclein can directly bind and disrupt mitochondria (Mullin and Schapira, 2013). $\alpha$-synuclein in other non-CNS immune cells in the peripheral systems could play an important role in the pathogenesis of PD and other synucleinopathies.

The levels of $\alpha$-synuclein and phagocytosis may be useful biomarkers in PD patients. PD involves $\alpha$-synuclein pathology and tissue dysfunction in multiple organs. $\alpha$-synuclein levels were elevated in monocytes and lymphocytes of sporadic $\mathrm{PD}$ patients when compared to control subjects. Increased $\alpha$-synuclein staining was confirmed by immunoblot analysis of a subset of the peripheral blood mononuclear cells. Elevated $\alpha$-synuclein is not limited to familial PD, but is also observed in sporadic PD. However, reports regarding the expression of $\alpha$-synuclein in microglial cells and macrophages are conflicting. In an interesting study, Zhou et al. (2016) have utilized the MPTP mouse model of PD to decipher the role of $\alpha$-synuclein and mir-7 on the activation of NACHT, LRR and PYD domains-containing protein 3 (NLRP3) inflammasome and neuroinflammation. These studies suggest that mir-7 targets NLRP3 expression besides $\alpha$-synuclein and modulates NLRP3 inflammasome mediated inflammation. Increased $\alpha$-synuclein expression with age has been reported in macrophages; however, other studies have reported no expression at all. Previous studies have shown that misfolded $\alpha$-synuclein directly activates microglia inducing the production and release of the proinflammatory cytokines while increasing antioxidant enzyme expression. In the nigrostriatal system, dopamine is a prominent source of ROS. Therefore, the nigrostriatal system may exhibit enhanced vulnerability and be more prone to PD because this region has high levels of oxidative stress and is enriched in $\alpha$-synuclein as well as dopamine. $\alpha$-synuclein is the major component of Lewy bodies responsible for Lewy neuritis in sporadic PD, dementia with Lewy Bodies and a Lewy Body variant of $\mathrm{AD}$. Further, $\alpha$-synuclein is implicated in glia activation, oxidative stress, neuronal dysfunction, neuroinflammation and neurodegeneration (Béraud et al., 2013). We have previously shown that $\alpha$-synuclein induced chemokine IL-8 release from cultured human mast cells in vitro (Kempuraj et al., 2015) indicating that $\alpha$-synuclein released in the brain could activate mast cells in inflammatory conditions in vivo. A peripheral source of $\alpha$-synuclein could influence neuroinflammation and neurodegeneration in the CNS.

\section{GMF IN NEUROINFLAMMATION}

GMF is a novel multifunctional, brain-dominant protein first discovered (Lim et al., 1989, 1990a; Kaplan et al., 1991; Zaheer et al., 1993), purified, sequenced, and cloned in our laboratory (Lim et al., 1989, 1990b). GMF is mainly expressed in the glia in the CNS and is an important factor in neuroinflammation and neurodegeneration in the CNS (Zaheer et al., 2007). We have previously reported increased expression of GMF in the CNS of neurodegenerative and autoimmune disorders (Zaheer 
et al., 2011; Thangavel et al., 2012; Stolmeier et al., 2013; Kempuraj et al., 2016b). More recently we have also shown that upregulation of GMF is associated with downregulation of UCPs in AD brains (Thangavel et al., 2017). Other investigators have previously demonstrated the expression of GMF in the extra CNS cells/tissues such as in macrophages and peripheral organs (Kaimori et al., 2003; Utsuyama et al., 2003). GMF is a proinflammatory mediator released from glial cells (Zaheer et al., 2008a), and GMF-knockout (GMF-KO) mice showed reduced glial activation and significantly suppressed proinflammatory molecules expression after $A \beta$ infusion when compared to wild type mice (Zaheer et al., 2008b). Primary astrocyte and microglia cultures obtained from GMF-KO mice showed a reduced expression of inflammatory cytokines and chemokines compared to glia obtained from wild type cells, and returned to control levels after reconstitution with an adenoviral construct (Zaheer et al., 2008b). GMF activates astrocytes through p38 mitogenactivated protein kinase (MAPK) and NF- $\kappa \mathrm{B}$ signaling pathways (Zaheer et al., 2001, 2007). GMF activates both human and mouse mast cells. Further, our previous studies have shown that BMMCs obtained from GMF-KO mice released less CCL2 than BMMCs obtained from wild type mice. We have also shown that lack of GMF in astrocytes increases antioxidant level and reduces the production of ROS in $\mathrm{MPP}^{+}$-mediated toxicity (Khan et al., 2014). We have previously shown the expression of GMF in the cultured mouse and human mast cells by immunocytochemistry (Kempuraj et al., 2015). The lack of GMF reduces the release of inflammatory molecules from mast cells. We have shown that GMF, $\alpha$-synuclein, $\mathrm{MPP}^{+}$, and IL-33 significantly increased the release of IL-8 from human mast cells (Kempuraj et al., 2015). Further, we have shown that incubation of human mast cells with IL-33 upregulates the expression of GMF indicating that GMF expression could be increased during mast cell activation in neurodegenerative diseases. Mast cells could release the stored or newly synthesized GMF during the neuroinflammatory conditions along with other proinflammatory molecules in response to $\mathrm{MPP}^{+}, \alpha$-synuclein, $\mathrm{A} \beta$ or other $\mathrm{PD}$ and $\mathrm{AD}$-relevant proinflammatory molecules.

\section{GMF Expression in Systemic Pathological Conditions}

The expression of GMF could be enhanced in several systemic inflammatory diseases. An earlier study has shown that GMF enhances oxidative stress in renal diseases. GMF is normally absent in the kidney but the expression of GMF is inducible in the proximal renal tubules under the stress of proteinuria and in non-brain tissues (Imai et al., 2015). Thymus shows the expression of GMF, which is important in T cell development (Utsuyama et al., 2003). GMF overexpression in non-brain cells increases the vulnerability to oxidative stress and apoptosis (Kaimori et al., 2003). Another study showed up-regulation of GMF expression in the lesions of 246 human serous ovarian carcinoma (SOC) patients and that high GMF expression exhibited lower disease-free and overall survival rates (Li et al., 2010). Other studies have reported that GMF- $\gamma$ increased in the cardiac ischemia model with inflammation and angiogenesis (Ikeda et al., 2006). Furthermore, GMF- $\gamma$ is an important regulator of neutrophil chemotaxis (Aerbajinai et al., 2011). GMF released from systemic inflammation could increase the GMF level in the periphery and this increased GMF may enter into the brain and induce or augment neuroinflammation by activating glia, neurons, mast cells and T-cells. Thus, peripheral-derived GMF may also increase the neuroinflammatory mechanisms in neurodegenerative diseases similar to other inflammatory mediators as shown in Figure 2.

\section{NEUROPEPTIDES SP AND CRH IN NEUROINFLAMMATION}

SP is a neurotrophic and neuroprotective factor and can directly modulate glial functions in the brain (Severini et al., 2016). SP is an important proinflammatory neuropeptide that can activate glia and induce neurodegeneration in the CNS ( $\mathrm{Li} \mathrm{W}$. W. et al., 2015). Elevated levels of SP have been reported in the CSF of $\mathrm{AD}$ patients when compared with dementias and control subjects. Further, this increase corresponded to the increased level of $\mathrm{A} \beta 1-42$ in the CSF of $\mathrm{AD}$ patients (Johansson et al., 2015). However, a reduced level of SP was also reported in the brain and CSF of AD patients (Severini et al., 2016). SP concentration in the subsantia nigra is high and this may be responsible for the increased microglia in this region (Wang et al., 2015). Neuropeptides are involved in neurogenic inflammation and many neuropeptides, including SP, induce mast cell activation and release several neuroinflammatory cytokines, chemokines, tryptase and histamine (Nicoletti et al., 2012). SP is the most abundant neuropeptide in the CNS and is distributed in the peripheral tissues. It has been demonstrated that SP enhances human $\mathrm{T}$-cell proliferation responses and causes an increased synthesis of CC and CXC chemokines. In addition, SP and $\mathrm{CRH}$ also induce the synthesis and release of cytokines/chemokines such as TNF- $\alpha$, CCL2, CCL3, CCL5, GM-CSF, CXCL8, proteases tryptase and chymase, histamine, leukotrienes and $\mathrm{PGD}_{2}$ from mast cells (Katsanos et al., 2008). SP is a mediator of neuroinflammation as well as a key element in striatonigral circuitry. PD patients and animal models of PD show dopaminergic neuronal death in the substantia nigra region of the brain. SP increases dopaminergic neuronal death directly and is also induced by LPS or $\mathrm{MPP}^{+}$ (Wang et al., 2014). Dopamine induces the release of SP in substantia nigra and the SP potentiate dopamine release in a positive feedback pathway mechanism (Thornton et al., 2010). The substantia nigra has bidirectional neuronal connections with the striatum. Striatal neurons innervate the substantia nigra pars compacta, releasing SP and activating inflammatory cells. We and others have previously shown that several neuropeptides such as SP (Cocchiara et al., 1999; Azzolina et al., 2003; Kulka et al., 2008; Taracanova et al., 2017) and CRH (Theoharides et al., 2004; Alysandratos et al., 2012) are known to activate mast cells to release proinflammatory cytokines and chemokines (Kulka et al., 2008; Shaik-Dasthagirisaheb et al., 2013). Mast cell mediators such as histamine in turn activate microglia and release neuroinflammatory mediators in the brain 
(Zhu et al., 2014). SP and CRH are important mediators of neuroinflammation and BBB dysfunctions (Esposito et al., 2002; Thornton and Vink, 2012). Increased SP levels have been reported in 6-hydroxydopamine hydrochloride (6-OHDA)induced PD animal models. A recent report shows that an integrated microfluidic immuno chip can be used as a sensitive, rapid and quantitative detection of SP in the serum of neuroinflammatory conditions (Horak et al., 2014). Previous study has shown that treatment with an SP receptor antagonist is neuroprotective in the intra striatal 6-hydroxydopamine-induced PD (Thornton and Vink, 2012). However, some studies reported decreased SP levels in the substantia nigra of PD (Fernandez et al., 1992). SP can activate glial nicotinamide adenine dinucleotide phosphate (NADPH) oxidase to release ROS (Block et al., 2006).

$\mathrm{CRH}$ is the principal coordinator of the stress response by activating the hypothalamo-pituitary-adrenal (HPA) axis (Dedic et al., 2017). CRH is released by neurons in the hypothalamus and in extra CNS cells including mast cells (Kempuraj et al., 2004b; Pardon, 2011). CRH could regulate neuroinflammation by increasing the apoptosis of microglia and activation of mast cells (Ock et al., 2006). CRH can activate microglia through CRH R and release inflammatory mediators (Kritas et al., 2014b). Moreover, SP is known to induce the expression of $\mathrm{CRH}$ in glia (Hamke et al., 2006). Emotional/chronic stress enhance glial activation and exacerbates neuronal death through inflammation in the substantia nigra of the PD brain (De Pablos et al., 2014). A case report suggested that major stress could have triggered PD in a young woman (Zou et al., 2013). Stress-induced striatal damage, with subsequent worsening of motor symptoms has been reported in animal models of PD. CRH is also implicated in $\mathrm{AD}$ pathogenesis including the generation of $\mathrm{A} \beta$ (Pardon, 2011; Marcello et al., 2015). CRH could stimulate mast cells and glial activation and their proliferations in neuroinflammation (Theoharides et al., 2013). We have shown the expression of $\mathrm{CRH}$ as well as $\mathrm{CRH} \mathrm{R}$ in mast cells (Kempuraj et al., 2004b; Cao et al., 2005; Papadopoulou et al., 2005). CRH released from activated mast cells could also activate glial cells in neurodegenerative conditions (Kempuraj et al., 2004b). SP also induces $\mathrm{CRH}$ receptor expression on mast cells (Asadi et al., 2012). In fact, administration of inflammatory cytokines induces a depressive disorder similar to the one induced by stressors (Anisman et al., 2002; Gibb et al., 2009; Anisman and Hayley, 2012; Hayley et al., 2013). Thus, stressful conditions can activate peripheral mast cells; activate $\mathrm{CRH}$ and SP pathways leading to increased $\mathrm{BBB}$ permeability, increased glial activation and more severe neuroinflammation and neurodegenerative diseases.

\section{DOPAMINE IN NEUROINFLAMMATION}

Neurotransmitter dopamine is implicated in the pathogenesis of PD and in AD (Bisaglia et al., 2014; Nobili et al., 2017). Self-oxidation of dopamine to dopamine quinone, aminochrome and 5,6-indolequinone mediate $\mathrm{PD}$ pathogenesis since aminochrome induces mitochondrial dysfunctions (SeguraAguilar et al., 2014). The dying neurons in PD release neuromelanin, which induces glial cells activation, and augments neuroinflammatory reactions. Substantia nigra dopamine levels are implicated in 6-OHDA induced recruitment of peripheral inflammatory cells into the nigrostriatal regions in the brain (Espinosa-Oliva et al., 2014). Dopamine can activate microglia to release inflammatory mediators and increase oxidative stress as they express receptors for dopamine (Labandeira-Garcia et al., 2013; Lee, 2013). Mast cells also can synthesize and store dopamine in secretory granules and tyrosine hydroxylase, a key precursor enzyme in dopamine biosynthesis (Freeman et al., 2001; Ronnberg et al., 2012). The amount of dopamine synthesis and storage increases along with mast cell maturation (Ronnberg et al., 2012). Mast cells express D1-like dopamine receptors (Mori et al., 2013) and vesicular monoamine transporters (VMAT2). The D1-like dopamine receptor and VMAT2 transport dopamine/MPP ${ }^{+}$in mast cells could induce the generation of ROS and the release of inflammatory mediators. D1-like receptors play an important role in allergic reactions in the skin through the T-helper (Th2) formation and mast cell activation (Mori et al., 2013). The expression of tyrosine hydroxylase is induced during mast cell maturation (Ronnberg et al., 2012). Mast cell activation can release dopamine along with other inflammatory mediators (Freeman et al., 2001) and augment neuroinflammation. Dopamine influences mast cell interaction with $\mathrm{T}$ cells. Thus, peripheral as well as brain mast cell activation can influence neuroinflammatory mechanisms.

\section{MECHANISMS BY WHICH PERIPHERAL INFLAMMATORY FACTORS AND INFLAMMATORY CELLS AUGMENT NEUROINFLAMMATION}

$\mathrm{AD}$ patients show abnormalities in peripheral tissues, immune and inflammatory cells in addition to the pathological changes observed in the brain regions (Khan and Alkon, 2014). Drugs targeting neuroinflammation represent next generation of therapeutic agents for treating $\mathrm{AD}$ and $\mathrm{PD}$ (Bronzuoli et al., 2016; McKenzie et al., 2017). Studies have shown that peripheral inflammation exacerbates neuroinflammation and neurodegeneration in the brain including its substantia nigra region (Perry, 2010; Villarán et al., 2010; Machado et al., 2011; Hernández-Romero et al., 2012; Träger and Tabrizi, 2013). Animal studies have shown systemic inflammation activates microglia in the brain and releases inflammatory mediators (Hoogland et al., 2015). High levels of IL-6, TNF- $\alpha$ and CCL2 in the plasma and serum of $\mathrm{AD}, \mathrm{PD}$ and MS patients as well as in various systemic inflammatory diseases can induce the neurodegenerative pathways in these diseases (Träger and Tabrizi, 2013). Systemic inflammation also increases BBB permeability in AD (Takeda et al., 2013). Normally BBB, formed by endothelial cells and astrocyte end-feet, restricts transfer of larger molecules and cells into the brain. Cytokines/chemokines and other proinflammatory molecules have been shown to cross BBB by an active transport mechanism (Banks et al., 1995) or through circumventricular organs that lack BBB (Perry et al., 
2007). The peripheral immune and inflammatory mediators can interact with brain $\mathrm{BBB}$ endothelial cells and induce the release of additional inflammatory molecules including $\mathrm{PGD}_{2}$ into the brain (Ek et al., 2001). Systemic immune cells such as T cells can infiltrate into the brain through the $\mathrm{BBB}$ via choroid plexus or CSF that could induce neurodegeneration (Ransohoff et al., 2003; Park et al., 2016). Peripheral inflammation is also translated to the brain through the vagus nerve by neural reflex (Tracey, 2009). As the BBB is disrupted in neurodegenerative diseases, the flow of immune cells and inflammatory molecules across the $\mathrm{BBB}$ is increased and thereby increases neuroinflammation (Kortekaas et al., 2005; Takeda et al., 2013). Several previous reports indicate that mast cell activation (Karagkouni et al., 2013; Zhang et al., 2016), as well as peripheral inflammation influences $\mathrm{BBB}$ disruption to increase the permeability of inflammatory mediators and immune cell infiltration into the brain thereby spreading peripheral inflammation into the brain (Takeda et al., 2013). Peripheral inflammation due to LPS injection increases neuroinflammation without increasing $\mathrm{A} \beta$ level in the $\mathrm{AD}$ mouse model, indicating neuroinflammation could increase without increasing the $A \beta$ level in the brain (Takeda et al., 2013). A recent article reported that immunotherapy which induces $A \beta$ clearance alone does not improve cognitive improvement in $\mathrm{AD}$ patients and indicates the contribution of systemic inflammation in these patients (Goldeck et al., 2016). Activated microglia and astrocytes release inflammatory mediators, which enter the peripheral system through the defective $\mathrm{BBB}$ and recruit immune cells to the brain, thereby exacerbating neuroinflammatory mechanisms (Goldeck et al., 2016).

The brain was originally considered as an immunologically privileged organ but now it is well known that the peripheral immune system and the brain communicate through several pathways (Ransohoff and Brown, 2012). We have previously shown that the presence of a tumor in the brain affects peripheral blood immune parameters (Kempuraj et al., 2004a). Several peripheral inflammatory conditions (Figure 1) could activate mast cells and release proinflammatory and neurotoxic mediators such as GMF, $\alpha$-synuclein, CRH, neurotensin, proteases, cytokines and chemokines. These mediators can cause up-regulation of the neuroinflammatory mechanisms (Träger and Tabrizi, 2013) by the following mechanisms. These mediators can induce BBB breakdown, enter into the brain and activate glia and neurons to release various neuroinflammatory mediators. Further peripheral mast cells, mast cell progenitor cells and T-cells enter into the brain, proliferate, mature and secrete additional inflammatory mediators. Inflammatory mediators released from these cells activate glia and neurons to secrete additional inflammatory mediators including GMF and neuropeptides reduce UCP expression, and induce neuronal damage and neurodegeneration. Further, glia and mast cells reactivate each other in the brain through co-stimulatory molecules CD40/CD154 or inflammatory mediators such as TNF- $\alpha$, IL-1 $\beta$ or IL-33. Mast cell tryptase can act on the neurons through PAR2. Mast cells can be reactivated by its own mediators in an autocrine and paracrine manner and exacerbate neuroinflammatory pathways. $\alpha$-synuclein or $\mathrm{MPP}^{+}$from glia or extracellular $\mathrm{A} \beta 1-42$ can activate mast cells to release neuroinflammatory mediators in $\mathrm{PD}$ and $\mathrm{AD}$, respectively. Additionally, several inflammatory mediators from peripheral tissue can alter $\mathrm{BBB}$, enter the brain and activate various neuroinflammatory pathways. Furthermore, inflammatory mediators released from activated microglia and astrocytes enter into peripheral system through defective BBB, activate, and recruit immune and inflammatory cells towards the inflammatory site in the brain. However, the influence of peripheral factors on neuroinflammation could vary from individual to individual and time to time in the same individual, which is much like the situation where some people develop allergic reactions in a given place, even though all people living in that area are exposed to the same external environment such as pollen in the spring. Additionally, the severity and the duration of allergic reactions also varies in these people. Another example is the cancer metastasis to the brain. Metastasis of cancer also varies from person to person based on the immune condition of patients. This is because; mast cell numbers and the extent of mast cell activation-mediated disease severity also varies from person to person.

\section{FUTURE DIRECTION}

\section{A New Approach Is Required to Slow Down the Neuronal Aging Process and Enhance the Neuronal Repair Processes to Treat Neurodegenerative Diseases}

Regeneration of the neuronal tissue is limited following any CNS injury. The role of neurite outgrowth inhibitors such as Nogo proteins in inhibiting the neuro regeneration has been reported (Wang et al., 2012). However, in order to achieve efficacious treatment options for the neurodegenerative diseases, it is necessary to explore newer approaches to slowdown the aging process of neurons, replace the dead neurons with the new neurons, and also to repair partially damaged neurons by self-recovery/regenerative mechanisms. Our current knowledge on the interactions between the peripheral immune and inflammatory components with the neuroinflammatory mechanism is still limited (Holmes and Butchart, 2011). Currently most of the laboratories working on the neurodegenerative diseases are dealing primarily with the brain mechanisms but not on the bidirectional communications with the peripheral immune and inflammatory mechanisms. Future research should explore the option for the adult neurons to multiply, grow and make neuronal connections in the adult CNS as seen in the fetal stage. A potentially beneficial approach would be to harness the unlimited potential of patient-specific induced pluripotent stem cells to generate various types of neurons for treatment of neurodegenerative diseases. Multiple inflammatory mediators and multiple immune/inflammatory cells such as mast cells are involved in the pathogenesis of neurodegenerative diseases. A better understanding of the brain and the peripheral immune and inflammatory intertwined pathways is imperative for the effective therapies of brain repair and regeneration. 


\section{CONCLUSION}

Although the mechanisms of neuroinflammation mediated neurodegeneration is not yet clearly understood, neuroinflammation is considered an important contributing factor for the neuronal death in the brain of age-related neurodegenerative disease. Peripheral immune response/activation and peripheral inflammation could generate several proinflammatory and neuro cytotoxic mediators. These peripheral inflammatory factors as well as peripheral inflammatory cells such as mast cells and $\mathrm{T}$ cells enter the brain. Further, these cells and inflammatory mediators could directly or through astrocyte, microglia, neurons and mast cell activation induce and sustain chronic neuroinflammation leading to neuronal death in the brain. Although suppression of neuroinflammation could reduce the severity of disease symptoms and neurodegeneration, the aging factor and immune

\section{REFERENCES}

Abbott, N. J. (2000). Inflammatory mediators and modulation of blood-brain barrier permeability. Cell. Mol. Neurobiol. 20, 131-147. doi: 10.1023/A:1007074420772

Aerbajinai, W., Liu, L., Chin, K., Zhu, J., Parent, C. A., and Rodgers, G. P. (2011). Glia maturation factor- $\gamma$ mediates neutrophil chemotaxis. J. Leukoc. Biol. 90, 529-538. doi: 10.1189/jlb.0710424

Aheng, C., Ly, N., Kelly, M., Ibrahim, S., Ricquier, D., Alves-Guerra, M. C., et al. (2011). Deletion of UCP2 in iNOS deficient mice reduces the severity of the disease during experimental autoimmune encephalomyelitis. PLoS One 6:e22841. doi: 10.1371/journal.pone. 0022841

Allan, S. M., and Rothwell, N. J. (2001). Cytokines and acute neurodegeneration. Nat. Rev. Neurosci. 2, 734-744. doi: 10.1038/sj.mp.4000223

Allan, S. M., and Rothwell, N. J. (2003). Inflammation in central nervous system injury. Philos. Trans. R. Soc. Lond. B Biol. Sci. 358, 1669-1677. doi: 10.1098/rstb. 2003.1358

Allan, S. M., Tyrrell, P. J., and Rothwell, N. J. (2005). Interleukin-1 and neuronal injury. Nat. Rev. Immunol. 5, 629-640. doi: 10.1038/nri1664

Alysandratos, K. D., Asadi, S., Angelidou, A., Zhang, B., Sismanopoulos, N., Yang, H., et al. (2012). Neurotensin and CRH interactions augment human mast cell activation. PLoS One 7:e48934. doi: 10.1371/journal.pone. 0048934

Andrews, Z. B., Horvath, B., Barnstable, C. J., Elsworth, J., Yang, L., Beal, M. F., et al. (2005). Uncoupling protein-2 is critical for nigral dopamine cell survival in a mouse model of Parkinson's disease. J. Neurosci. 25, 184-191. doi: 10.1523/JNEUROSCI.4269-04.2005

Anisman, H., and Hayley, S. (2012). Inflammatory factors contribute to depression and its comorbid conditions. Sci. Signal. 5:pe45. doi: 10.1126/scisignal.2003579

Anisman, H., Hayley, S., Turrin, N., and Merali, Z. (2002). Cytokines as a stressor: implications for depressive illness. Int. J. Neuropsychopharmacol. 5, 357-373. doi: 10.1017/s1461145702003097

Asadi, S., Alysandratos, K. D., Angelidou, A., Miniati, A., Sismanopoulos, N., Vasiadi, M., et al. (2012). Substance P (SP) induces expression of functional corticotropin-releasing hormone receptor-1 (CRHR-1) in human mast cells. J. Invest. Dermatol. 132, 324-329. doi: 10.1038/jid.2011. 334

Ascolani, A., Balestrieri, E., Minutolo, A., Mosti, S., Spalletta, G., Bramanti, P., et al. (2012). Dysregulated NF- $\mathrm{B}$ pathway in peripheral mononuclear cells of Alzheimer's disease patients. Curr. Alzheimer Res. 9, 128-137. doi: 10.2174/156720512799015091

Azzolina, A., Bongiovanni, A., and Lampiasi, N. (2003). Substance P induces TNF- $\alpha$ and IL-6 production through NF- $\kappa$ B in peritoneal mast cells. Biochim. Biophys. Acta 1643, 75-83. doi: 10.1016/j.bbamcr.2003.09.003 disorder could continue to influence neurodegeneration. Therefore, novel approaches are required to better understand the communication pathways between the systemic and CNS immune system for the development of new and effective strategies to limit neurodegeneration and promote neuroregeneration in the brain.

\section{AUTHOR CONTRIBUTIONS}

DK and AZ wrote and critically edited the manuscript. RT, GPS, SZ, MEA, SPR, HZ, DS, PAN and SI edited the manuscript.

\section{ACKNOWLEDGMENTS}

This study was carried out by research grants from the Veteran Affairs Merit Award I01BX002477, and the National Institutes of Health Grants AG048205 and NS073670 to AZ.

Banks, W. A., Kastin, A. J., and Broadwell, R. D. (1995). Passage of cytokines across the blood-brain barrier. Neuroimmunomodulation 2, 241-248. doi: $10.1159 / 000097202$

Becher, B., Spath, S., and Goverman, J. (2017). Cytokine networks in neuroinflammation. Nat. Rev. Immunol. 17, 49-59. doi: 10.1038/nri.2016.123

Béraud, D., Hathaway, H. A., Trecki, J., Chasovskikh, S., Johnson, D. A., Johnson, J. A., et al. (2013). Microglial activation and antioxidant responses induced by the Parkinson's disease protein $\alpha$-synuclein. J. Neuroimmune Pharmacol. 8, 94-117. doi: 10.1007/s11481-012-9401-0

Bisaglia, M., Filograna, R., Beltramini, M., and Bubacco, L. (2014). Are dopamine derivatives implicated in the pathogenesis of Parkinson's disease? Ageing Res. Rev. 13C, 107-114. doi: 10.1016/j.arr.2013.12.009

Block, M. L., Li, G., Qin, L., Wu, X., Pei, Z., Wang, T., et al. (2006). Potent regulation of microglia-derived oxidative stress and dopaminergic neuron survival: substance P vs. dynorphin. FASEB J. 20, 251-258. doi: 10.1096/fj.05$4553 \mathrm{com}$

Blum-Degen, D., Müller, T., Kuhn, W., Gerlach, M., Przuntek, H., and Riederer, P. (1995). Interleukin-1 $\beta$ and interleukin-6 are elevated in the cerebrospinal fluid of Alzheimer's and de novo Parkinson's disease patients. Neurosci. Lett. 202, 17-20. doi: 10.1016/0304-3940(95)12192-7

Bollaerts, I., Van Houcke, J., Andries, L., De Groef, L., and Moons, L. (2017). Neuroinflammation as fuel for axonal regeneration in the injured vertebrate central nervous system. Mediators Inflamm. 2017:9478542. doi: $10.1155 / 2017 / 9478542$

Bronzuoli, M. R., Iacomino, A., Steardo, L., and Scuderi, C. (2016). Targeting neuroinflammation in Alzheimer's disease. J. Inflamm. Res. 9, 199-208. doi: $10.2147 /$ JIR.S86958

Brough, D., Rothwell, N. J., and Allan, S. M. (2015). Interleukin-1 as a pharmacological target in acute brain injury. Exp. Physiol. 100, 1488-1494. doi: 10.1113/EP085135

Brown, M. A., and Hatfield, J. K. (2012). Mast cells are important modifiers of autoimmune disease: with so much evidence, why is there still controversy? Front. Immunol. 3:147. doi: 10.3389/fimmu.2012.00147

Cao, J., Papadopoulou, N., Kempuraj, D., Boucher, W. S., Sugimoto, K., Cetrulo, C. L., et al. (2005). Human mast cells express corticotropin-releasing hormone $(\mathrm{CRH})$ receptors and $\mathrm{CRH}$ leads to selective secretion of vascular endothelial growth factor. J. Immunol. 174, 7665-7675. doi: 10.4049/jimmunol. 174.12.7665

Cardoso, S., Correia, S., Carvalho, C., Candeias, E., Placido, A. I., Duarte, A. I., et al. (2015). Perspectives on mitochondrial uncoupling proteins-mediated neuroprotection. J. Bioenerg. Biomembr. 47, 119-131. doi: 10.1007/s10863-0149580-x

Cardoso, A. L., Guedes, J. R., Pereira De Almeida, L., and Pedroso De Lima, M. C. (2012). miR-155 modulates microglia-mediated immune response by down-regulating SOCS-1 and promoting cytokine and nitric 
oxide production. Immunology 135, 73-88. doi: 10.1111/j.1365-2567.2011.0 3514. $\mathrm{x}$

Chen, W.-W., Zhang, X., and Huang, W.-J. (2016). Role of neuroinflammation in neurodegenerative diseases (Review). Mol. Med. Rep. 13, 3391-3396. doi: 10.3892/mmr.2016.4948

Chikahisa, S., Kodama, T., Soya, A., Sagawa, Y., Ishimaru, Y., Sei, H., et al. (2013). Histamine from brain resident MAST cells promotes wakefulness and modulates behavioral states. PLoS One 8:e78434. doi: 10.1371/journal.pone. 0078434

Chung, Y. C., Ko, H. W., Bok, E., Park, E. S., Huh, S. H., Nam, J. H., et al. (2010). The role of neuroinflammation on the pathogenesis of Parkinson's disease. BMB Rep. 43, 225-232. doi: 10.5483/BMBRep.2010.43.4.225

Cocchiara, R., Lampiasi, N., Albeggiani, G., Bongiovanni, A., Azzolina, A., and Geraci, D. (1999). Mast cell production of TNF- $\alpha$ induced by substance P evidence for a modulatory role of substance P-antagonists. J. Neuroimmunol. 101, 128-136. doi: 10.1016/s0165-5728(99)00138-1

Conti, P., and Kempuraj, D. (2016). Important role of mast cells in multiple sclerosis. Mult. Scler. Relat. Disord. 5, 77-80. doi: 10.1016/j.msard.2015.11.005

Culley, D. J., Snayd, M., Baxter, M. G., Xie, Z., Lee, I. H., Rudolph, J., et al. (2014). Systemic inflammation impairs attention and cognitive flexibility but not associative learning in aged rats: possible implications for delirium. Front. Aging Neurosci. 6:107. doi: 10.3389/fnagi.2014.00107

Cunningham, C., Campion, S., Lunnon, K., Murray, C. L., Woods, J. F., Deacon, R. M., et al. (2009). Systemic inflammation induces acute behavioral and cognitive changes and accelerates neurodegenerative disease. Biol. Psychiatry 65, 304-312. doi: 10.1016/j.biopsych.2008.07.024

Dantzer, R., Konsman, J. P., Bluthé, R. M., and Kelley, K. W. (2000). Neural and humoral pathways of communication from the immune system to the brain: parallel or convergent? Auton. Neurosci. 85, 60-65. doi: 10.1016/s15660702(00)00220-4

Dedic, N., Chen, A., and Deussing, J. M. (2017). The CRF family of neuropeptides and their receptors-mediators of the central stress response. Curr. Mol. Pharmacol. doi: 10.2174/1874467210666170302104053 [Epub ahead of print].

Dendrou, C. A., McVean, G., and Fugger, L. (2016). Neuroinflammation-using big data to inform clinical practice. Nat. Rev. Neurol. 12, 685-698. doi: 10.1038/nrneurol.2016.171

De Pablos, R. M., Herrera, A. J., Espinosa-Oliva, A. M., Sarmiento, M., Muñoz, M. F., Machado, A., et al. (2014). Chronic stress enhances microglia activation and exacerbates death of nigral dopaminergic neurons under conditions of inflammation. J. Neuroinflammation 11:34. doi: 10.1186/17422094-11-34

De Simone, R., Ajmone-Cat, M. A., Pandolfi, M., Bernardo, A., De Nuccio, C., Minghetti, L., et al. (2015). The mitochondrial uncoupling protein-2 is a master regulator of both M1 and M2 microglial responses. J. Neurochem. 135, 147-156. doi: 10.1111/jnc.13244

Desplats, P., Lee, H.-J., Bae, E.-J., Patrick, C., Rockenstein, E., Crews, L., et al. (2009). Inclusion formation and neuronal cell death through neuron-to-neuron transmission of $\alpha$-synuclein. Proc. Natl. Acad. Sci. U S A 106, 13010-13015. doi: 10.1073/pnas.0903691106

Dong, H., Zhang, X., and Qian, Y. (2014). Mast cells and neuroinflammation. Med. Sci. Monit. Basic Res. 20, 200-206. doi: 10.12659/MSMBR.893093

Ek, M., Engblom, D., Saha, S., Blomqvist, A., Jakobsson, P. J., and EricssonDahlstrand, A. (2001). Inflammatory response: pathway across the blood-brain barrier. Nature 410, 430-431. doi: 10.1038/35068632

Engelhardt, B., Vajkoczy, P., and Weller, R. O. (2017). The movers and shapers in immune privilege of the CNS. Nat. Immunol. 18, 123-131. doi: 10.1038/ni.3666

Enoksson, M., Lyberg, K., Moller-Westerberg, C., Fallon, P. G., Nilsson, G., and Lunderius-Andersson, C. (2011). Mast cells as sensors of cell injury through IL-33 recognition. J. Immunol. 186, 2523-2528. doi: 10.4049/jimmunol. 1003383

Espinosa-Oliva, A. M., De Pablos, R. M., Sarmiento, M., Villarán, R. F., CarrilloJiménez, A., Santiago, M., et al. (2014). Role of dopamine in the recruitment of immune cells to the nigro-striatal dopaminergic structures. Neurotoxicology 41, 89-101. doi: 10.1016/j.neuro.2014.01.006

Esposito, P., Chandler, N., Kandere, K., Basu, S., Jacobson, S., Connolly, R., et al. (2002). Corticotropin-releasing hormone and brain mast cells regulate bloodbrain-barrier permeability induced by acute stress. J. Pharmacol. Exp. Ther. 303, 1061-1066. doi: 10.1124/jpet.102.038497
Fernandez, A., de Ceballos, M. L., Jenner, P., and Marsden, C. D. (1992). Striatal neuropeptide levels in Parkinson's disease patients. Neurosci. Lett. 145, 171-174. doi: 10.1016/0304-3940(92)90014-x

Ferrari, C. C., and Tarelli, R. (2011). Parkinson's disease and systemic inflammation. Parkinsons Dis. 2011:436813. doi: 10.4061/2011/436813

Freeman, J. G., Ryan, J. J., Shelburne, C. P., Bailey, D. P., Bouton, L. A., Narasimhachari, N., et al. (2001). Catecholamines in murine bone marrow derived mast cells. J. Neuroimmunol. 119, 231-238. doi: 10.1016/S01655728(01)00384-8

Galli, S. J., Grimbaldeston, M., and Tsai, M. (2008). Immunomodulatory mast cells: negative, as well as positive, regulators of immunity. Nat. Rev. Immunol. 8, 478-486. doi: 10.1038/nri2327

Gibb, J., Audet, M. C., Hayley, S., and Anisman, H. (2009). Neurochemical and behavioral responses to inflammatory immune stressors. Front. Biosci. (Schol. Ed.) 1, 275-295. doi: 10.2741/e26

Gilfillan, A. M., Austin, S. J., and Metcalfe, D. D. (2011). Mast cell biology: introduction and overview. Adv. Exp. Med. Biol. 716, 2-12. doi: 10.1007/978-14419-9533-9_1

Goldeck, D., Witkowski, J. M., Fülop, T., and Pawelec, G. (2016). Peripheral immune signatures in Alzheimer disease. Curr. Alzheimer Res. 13, 739-749. doi: 10.2174/1567205013666160222112444

Gu, Y., Yang, D. K., Spinas, E., Kritas, S. K., Saggini, A., Caraffa, A., et al. (2015). Role of TNF in mast cell neuroinflammation and pain. J. Biol. Regul. Homeost. Agents 29, 787-791.

Gualtierotti, R., Guarnaccia, L., Beretta, M., Navone, S. E., Campanella, R., Riboni, L., et al. (2017). Modulation of neuroinflammation in the central nervous system: role of chemokines and sphingolipids. Adv. Ther. 34, 396-420. doi: 10.1007/s12325-016-0474-7

Gurish, M. F., and Austen, K. F. (2001). The diverse roles of mast cells. J. Exp. Med. 194, F1-F5. doi: 10.1084/jem.194.1.f1

Hamke, M., Herpfer, I., Lieb, K., Wandelt, C., and Fiebich, B. L. (2006). Substance $\mathrm{P}$ induces expression of the corticotropin-releasing factor receptor 1 by activation of the neurokinin-1 receptor. Brain Res. 1102, 135-144. doi: 10.1016/j.brainres.2006.03.026

Hayley, S., and Anisman, H. (2005). Multiple mechanisms of cytokine action in neurodegenerative and psychiatric states: neurochemical and molecular substrates. Curr. Pharm. Des. 11, 947-962. doi: 10.2174/1381612053381611

Hayley, S., Scharf, J., and Anisman, H. (2013). Central administration of murine interferon- $\alpha$ induces depressive-like behavioral, brain cytokine and neurochemical alterations in mice: a mini-review and original experiments. Brain Behav. Immun. 31, 115-127. doi: 10.1016/j.bbi.2012.07.023

He, Q., Wang, Q., Yuan, C., and Wang, Y. (2017). Downregulation of miR$7116-5 \mathrm{p}$ in microglia by $\mathrm{MPP}^{+}$sensitizes TNF- $\alpha$ production to induce dopaminergic neuron damage. Glia 65, 1251-1263. doi: 10.1002/glia.23153

Hernández-Romero, M. C., Delgado-Cortés, M. J., Sarmiento, M., de Pablos, R. M., Espinosa-Oliva, A. M., Argüelles, S., et al. (2012). Peripheral inflammation increases the deleterious effect of CNS inflammation on the nigrostriatal dopaminergic system. Neurotoxicology 33, 347-360. doi: 10.1016/j.neuro.2012. 01.018

Héron, A., and Dubayle, D. (2013). A focus on mast cells and pain. J. Neuroimmunol. 264, 1-7. doi: 10.1016/j.jneuroim.2013.09.018

Ho, P. W., Ho, J. W., Liu, H.-F., So, D. H., Tse, Z. H., Chan, K. H., et al. (2012). Mitochondrial neuronal uncoupling proteins: a target for potential disease-modification in Parkinson's disease. Transl. Neurodegener. 1:3. doi: $10.1186 / 2047-9158-1-3$

Holmes, C., and Butchart, J. (2011). Systemic inflammation and Alzheimer's disease. Biochem. Soc. Trans. 39, 898-901. doi: 10.1042/BST0390898

Holmes, C., Cunningham, C., Zotova, E., Woolford, J., Dean, C., Kerr, S., et al. (2009). Systemic inflammation and disease progression in Alzheimer disease. Neurology 73, 768-774. doi: 10.1212/WNL.0b013e3181b6bb95

Holmes, C., El-Okl, M., Williams, A. L., Cunningham, C., Wilcockson, D., and Perry, V. H. (2003). Systemic infection, interleukin $1 \beta$, and cognitive decline in Alzheimer's disease. J. Neurol. Neurosurg. Psychiatry 74, 788-789. doi: 10.1136/jnnp.74.6.788

Hoogland, I. C., Houbolt, C., Van Westerloo, D. J., van Gool, W. A., and van de Beek, D. (2015). Systemic inflammation and microglial activation: systematic review of animal experiments. J. Neuroinflammation 12:114. doi: 10.1186/s12974-015-0332-6 
Horak, J., Dincer, C., Bakirci, H., and Urban, G. (2014). Sensitive, rapid and quantitative detection of substance $\mathrm{P}$ in serum samples using an integrated microfluidic immunochip. Biosens Bioelectron. 58C, 186-192. doi: 10.1016/j. bios.2014.02.058

Hösli, L., Hösli, E., Schneider, U., and Wiget, W. (1984). Evidence for the existence of histamine $\mathrm{H} 1$ - and $\mathrm{H} 2$-receptors on astrocytes of cultured rat central nervous system. Neurosci. Lett. 48, 287-291. doi: 10.1016/0304-3940(84)90052-1

Ikeda, K., Kundu, R. K., Ikeda, S., Kobara, M., Matsubara, H., and Quertermous, T. (2006). Glia maturation factor- $\gamma$ is preferentially expressed in microvascular endothelial and inflammatory cells and modulates actin cytoskeleton reorganization. Circ. Res. 99, 424-433. doi: 10.1161/01.res.0000237662. 23539.0b

Imai, R., Asai, K., Hanai, J., and Takenaka, M. (2015). Transgenic mice overexpressing glia maturation factor- $\beta$, an oxidative stress inducible gene, show premature aging due to Zmpste24 down-regulation. Aging 7, 486-499. doi: 10.18632/aging.100779

Johansson, P., Almqvist, E. G., Wallin, A., Johansson, J. O., Andreasson, U., Blennow, K., et al. (2015). Cerebrospinal fluid substance P concentrations are elevated in patients with Alzheimer's disease. Neurosci. Lett. 609, 58-62. doi: 10.1016/j.neulet.2015.10.006

Johnson, R. W., Arkins, S., Dantzer, R., and Kelley, K. W. (1997). Hormones, lymphohemopoietic cytokines and the neuroimmune axis. Comp. Biochem. Physiol. A Physiol. 116, 183-201. doi: 10.1016/s0300-9629(96)00277-0

Johnson, D., Yasui, D., and Seeldrayers, P. (1991). An analysis of mast cell frequency in the rodent nervous system: numbers vary between different strains and can be reconstituted in mast cell-deficient mice. J. Neuropathol. Exp. Neurol. 50, 227-234. doi: 10.1097/00005072-199105000-00005

Kaimori, J. Y., Takenaka, M., Nakajima, H., Hamano, T., Horio, M., Sugaya, T., et al. (2003). Induction of glia maturation factor- $\beta$ in proximal tubular cells leads to vulnerability to oxidative injury through the p38 pathway and changes in antioxidant enzyme activities. J. Biol. Chem. 278, 33519-33527. doi: $10.1074 /$ jbc.m301552200

Kalesnikoff, J., and Galli, S. J. (2008). New developments in mast cell biology. Nat. Immunol. 9, 1215-1223. doi: 10.1038/ni.f.216

Kandere-Grzybowska, K., Letourneau, R., Kempuraj, D., Donelan, J., Poplawski, S., Boucher, W., et al. (2003). IL-1 induces vesicular secretion of IL-6 without degranulation from human mast cells. J. Immunol. 171, 4830-4836. doi: 10.4049/jimmunol.171.9.4830

Kaplan, R., Zaheer, A., Jaye, M., and Lim, R. (1991). Molecular cloning and expression of biologically active human glia maturation factor- $\beta$. J. Neurochem. 57, 483-490. doi: 10.1111/j.1471-4159.1991.tb03777.x

Karagkouni, A., Alevizos, M., and Theoharides, T. C. (2013). Effect of stress on brain inflammation and multiple sclerosis. Autoimmun. Rev. 12, 947-953. doi: 10.1016/j.autrev.2013.02.006

Katsanos, G. S., Anogeianaki, A., Orso, C., Tetè, S., Salini, V., Antinolfi, P. L., et al. (2008). Mast cells and chemokines. J. Biol. Regul. Homeost. Agents 22, 145-151.

Kempuraj, D., Devi, R. S., Madhappan, B., Conti, P., Nazer, M. Y., Christodoulou, S., et al. (2004a). T lymphocyte subsets and immunoglobulins in intracranial tumor patients before and after treatment and based on histological type of tumors. Int. J. Immunopathol. Pharmacol. 17, 57-64. doi: 10.1177/039463200401700108

Kempuraj, D., Papadopoulou, N. G., Lytinas, M., Huang, M., KandereGrzybowska, K., Madhappan, B., et al. (2004b). Corticotropin-releasing hormone and its structurally related urocortin are synthesized and secreted by human mast cells. Endocrinology 145, 43-48. doi: 10.1210/en.2003-0805

Kempuraj, D., Khan, M. M., Thangavel, R., Xiong, Z., Yang, E., and Zaheer, A. (2013). Glia maturation factor induces interleukin-33 release from astrocytes: implications for neurodegenerative diseases. J. Neuroimmune Pharmacol. 8, 643-650. doi: 10.1007/s11481-013-9439-7

Kempuraj, D., Thangavel, R., Fattal, R., Pattani, S., Yang, E., Zaheer, S., et al. (2016a). Mast cells release chemokine CCL2 in response to parkinsonian toxin 1-methyl-4-phenyl-pyridinium $\left(\mathrm{MPP}^{+}\right)$. Neurochem. Res. 41, 1042-1049. doi: $10.1007 /$ s11064-015-1790-z

Kempuraj, D., Thangavel, R., Natteru, P. A., Selvakumar, G. P., Saeed, D., Zahoor, H., et al. (2016b). Neuroinflammation induces neurodegeneration. J. Neurol. Neurosurg. Spine 1:1003.

Kempuraj, D., Thangavel, R., Yang, E., Pattani, S., Zaheer, S., Santillan, D. A., et al. (2015). Dopaminergic toxin 1-methyl-4-phenylpyridinium, proteins $\alpha$-synuclein and glia maturation factor activate mast cells and release inflammatory mediators. PLoS One 10:e0135776. doi: 10.1371/journal.pone. 0135776

Khan, M. M., Kempuraj, D., Zaheer, S., and Zaheer, A. (2014). Glia maturation factor deficiency suppresses 1-methyl-4-phenylpyridinium-induced oxidative stress in astrocytes. J. Mol. Neurosci. 53, 590-599. doi: 10.1007/s12031-0130225-Z

Khan, T. K., and Alkon, D. L. (2014). Peripheral biomarkers of Alzheimer's disease. J Alzheimers Dis. 44, 729-744. doi: 10.3233/JAD-142262

Kielian, T. (2016). Multifaceted roles of neuroinflammation: the need to consider both sides of the coin. J. Neurochem. 136, 5-9. doi: 10.1111/jnc. 13530

Kim, D. Y., Hong, G. U., and Ro, J. Y. (2011). Signal pathways in astrocytes activated by cross-talk between of astrocytes and mast cells through CD40CD40L. J. Neuroinflammation 8:25. doi: 10.1186/1742-2094-8-25

Kong, W. L., Peng, Y. Y., and Peng, B. W. (2017). Modulation of neuroinflammation: role and therapeutic potential of TRPV1 in the neuroimmune axis. Brain Behav. Immun. 64, 354-366. doi: 10.1016/j.bbi.2017.03.007

Kortekaas, R., Leenders, K. L., van Oostrom, J. C., Vaalburg, W., Bart, J., Willemsen, A. T., et al. (2005). Blood-brain barrier dysfunction in parkinsonian midbrain in vivo. Ann. Neurol. 57, 176-179. doi: 10.1002/ana.20369

Kritas, S. K., Caraffa, A., Antinolfi, P., Saggini, A., Pantalone, A., Rosati, M., et al. (2014a). Nerve growth factor interactions with mast cells. Int. J. Immunopathol. Pharmacol. 27, 15-19. doi: 10.1177/039463201402700103

Kritas, S. K., Saggini, A., Cerulli, G., Caraffa, A., Antinolfi, P., Pantalone, A., et al. (2014b). Corticotropin-releasing hormone, microglia and mental disorders. Int. J. Immunopathol. Pharmacol. 27, 163-167. doi: 10.1177/039463201402700203

Kulka, M., Sheen, C. H., Tancowny, B. P., Grammer, L. C., and Schleimer, R. P. (2008). Neuropeptides activate human mast cell degranulation and chemokine production. Immunology 123, 398-410. doi: 10.1111/j.1365-2567.2007.02705.x

Kure, C., Timmer, J., and Stough, C. (2017). The immunomodulatory effects of plant extracts and plant secondary metabolites on chronic neuroinflammation and cognitive aging: a mechanistic and empirical review. Front. Pharmacol. 8:117. doi: 10.3389/fphar.2017.00117

Kvetnoi, I. M., Kvetnaia, T. V., Riadnova, I., Fursov, B. B., Ernandes-Jago, H., and Blesa, J. R. (2003). Expression of $\beta$-amyloid and tau-protein in mastocytes in Alzheimer disease. Arkh. Patol. 65, 36-39.

Labandeira-Garcia, J. L., Rodriguez-Pallares, J., Dominguez-Meijide, A., Valenzuela, R., Villar-Cheda, B., and Rodriguez-Perez, A. I. (2013). Dopamine-angiotensin interactions in the basal ganglia and their relevance for Parkinson's disease. Mov. Disord. 28, 1337-1342. doi: 10.1002/mds. 25614

Lee, M. (2013). Neurotransmitters and microglial-mediated neuroinflammation. Curr. Protein Pept. Sci. 14, 21-32. doi: 10.2174/1389203711314010005

Lee, H. J., Suk, J. E., Patrick, C., Bae, E. J., Cho, J. H., Rho, S., et al. (2010). Direct transfer of $\alpha$-synuclein from neuron to astroglia causes inflammatory responses in synucleinopathies. J. Biol. Chem. 285, 9262-9272. doi: 10.1074/jbc.M109. 081125

Lehrer, S. (2014). Nasal NSAIDs for Alzheimer's disease. Am. J. Alzheimers Dis. Other Demen. 29, 401-403. doi: 10.1177/1533317513518658

Li, W. W., Guo, T. Z., Shi, X., Sun, Y., Wei, T., Clark, D. J., et al. (2015). Substance $\mathrm{P}$ spinal signaling induces glial activation and nociceptive sensitization after fracture. Neuroscience 310, 73-90. doi: 10.1016/j.neuroscience.2015.09.036

Li, L., Sun, Q., Li, Y., Yang, Y., Yang, Y., Chang, T., et al. (2015). Overexpression of SIRT1 induced by resveratrol and inhibitor of miR-204 suppresses activation and proliferation of microglia. J. Mol. Neurosci. 56, 858-867. doi: 10.1007/s12031-015-0526-5

Li, Y. L., Ye, F., Cheng, X. D., Hu, Y., Zhou, C. Y., Lü, W. G., et al. (2010). Identification of glia maturation factor $\beta$ as an independent prognostic predictor for serous ovarian cancer. Eur. J. Cancer 46, 2104-2118. doi: 10.1016/j.ejca.2010.04.015

Li, N., Zhang, X., Dong, H., Hu, Y., and Qian, Y. (2017). Bidirectional relationship of mast cells-neurovascular unit communication in neuroinflammation and its involvement in POCD. Behav. Brain Res. 322, 60-69. doi: 10.1016/j.bbr.2017. 01.006

Lim, R., Liu, Y. X., and Zaheer, A. (1990a). Cell-surface expression of glia maturation factor $\beta$ in astrocytes. FASEB J. 4, 3360-3363. 
Lim, R., Zaheer, A., and Lane, W. S. (1990b). Complete amino acid sequence of bovine glia maturation factor $\beta$. Proc. Natl. Acad. Sci. U S A 87, 5233-5237. doi: $10.1073 /$ pnas.87.14.5233

Lim, R., Miller, J. F., and Zaheer, A. (1989). Purification and characterization of glia maturation factor $\beta$ : a growth regulator for neurons and glia. Proc. Natl. Acad. Sci. U S A 86, 3901-3905. doi: 10.1073/pnas.86.10.3901

Litteljohn, D., and Hayley, S. (2012). Cytokines as potential biomarkers for Parkinson's disease: a multiplex approach. Methods Mol. Biol. 934, 121-144. doi: 10.1007/978-1-62703-071-7_7

Litteljohn, D., Mangano, E., Clarke, M., Bobyn, J., Moloney, K., and Hayley, S. (2010). Inflammatory mechanisms of neurodegeneration in toxin-based models of Parkinson's disease. Parkinsons Dis. 2011:713517. doi: $10.4061 / 2011 / 713517$

Lucas, S. M., Rothwell, N. J., and Gibson, R. M. (2006). The role of inflammation in CNS injury and disease. Br. J. Pharmacol. 147, S232-S240. doi: 10.1038/sj. bjp.0706400

Machado, A., Herrera, A. J., Venero, J. L., Santiago, M., De Pablos, R. M., Villaran, R. F., et al. (2011). Peripheral inflammation increases the damage in animal models of nigrostriatal dopaminergic neurodegeneration: possible implication in Parkinson's disease incidence. Parkinsons Dis. 2011:393769. doi: 10.4061/2011/393769

Marcello, E., Gardoni, F., and Di Luca, M. (2015). Alzheimer's disease and modern lifestyle: what is the role of stress? J. Neurochem. 134, 795-798. doi: 10.1111/jnc. 13210

McCusker, R. H., and Kelley, K. W. (2013). Immune-neural connections: how the immune system's response to infectious agents influences behavior. J. Exp. Biol. 216, 84-98. doi: 10.1242/jeb.073411

McKenzie, J. A., Spielman, L. J., Pointer, C. B., Lowry, J. R., Bajwa, E., Lee, C. W., et al. (2017). Neuroinflammation as a common mechanism associated with the modifiable risk factors for Alzheimer's and Parkinson's diseases. Curr. Aging Sci. doi: 10.2174/1874609810666170315113244 [Epub ahead of print].

McManus, R. M., and Heneka, M. T. (2017). Role of neuroinflammation in neurodegeneration: new insights. Alzheimers Res. Ther. 9:14. doi: 10.1186/s13195-017-0241-2

Mekori, Y. A., and Metcalfe, D. D. (2000). Mast cells in innate immunity. Immunol. Rev. 173, 131-140. doi: 10.1034/j.1600-065X.2000.917305.x

Metz, M., Grimbaldeston, M. A., Nakae, S., Piliponsky, A. M., Tsai, M., and Galli, S. J. (2007). Mast cells in the promotion and limitation of chronic inflammation. Immunol. Rev. 217, 304-328. doi: 10.1111/j.1600-065x.2007. 00520.x

More, S. V., Kumar, H., Kim, I. S., Song, S. Y., and Choi, D. K. (2013). Cellular and molecular mediators of neuroinflammation in the pathogenesis of Parkinson's disease. Mediators Inflamm. 2013:952375. doi: 10.1155/2013/952375

Mori, T., Kabashima, K., Fukamachi, S., Kuroda, E., Sakabe, J., Kobayashi, M., et al. (2013). D1-like dopamine receptors antagonist inhibits cutaneous immune reactions mediated by Th2 and mast cells. J. Dermatol. Sci. 71, 37-44. doi: 10.1016/j.jdermsci.2013.03.008

Morita, H., Saito, H., Matsumoto, K., and Nakae, S. (2016). Regulatory roles of mast cells in immune responses. Semin Immunopathol. 38, 623-629. doi: 10.1007/s00281-016-0566-0

Mullin, S., and Schapira, A. (2013). $\alpha$-Synuclein and mitochondrial dysfunction in Parkinson's disease. Mol. Neurobiol. 47, 587-597. doi: 10.1007/s12035-0138394-x

Negre-Salvayre, A., Hirtz, C., Carrera, G., Cazenave, R., Troly, M., Salvayre, R., et al. (1997). A role for uncoupling protein-2 as a regulator of mitochondrial hydrogen peroxide generation. FASEB J. 11, 809-815.

Nelissen, S., Lemmens, E., Geurts, N., Kramer, P., Maurer, M., Hendriks, J., et al. (2013). The role of mast cells in neuroinflammation. Acta Neuropathol. 125, 637-650. doi: 10.1007/s00401-013-1092-y

Nicoletti, M., Neri, G., Maccauro, G., Tripodi, D., Varvara, G., Saggini, A., et al. (2012). Impact of neuropeptide substance P an inflammatory compound on arachidonic acid compound generation. Int. J. Immunopathol. Pharmacol. 25, 849-857. doi: 10.1177/039463201202500403

Niederhoffer, N., Levy, R., Sick, E., Andre, P., Coupin, G., Lombard, Y., et al. (2009). Amyloid $\beta$ peptides trigger CD47-dependent mast cell secretory and phagocytic responses. Int. J. Immunopathol. Pharmacol. 22, 473-483. doi: $10.1177 / 039463200902200224$
Nobili, A., Latagliata, E. C., Viscomi, M. T., Cavallucci, V., Cutuli, D., Giacovazzo, G., et al. (2017). Dopamine neuronal loss contributes to memory and reward dysfunction in a model of Alzheimer's disease. Nat. Commun. 8:14727. doi: $10.1038 /$ ncomms 14727

Normoyle, K. P., Kim, M., Farahvar, A., Llano, D., Jackson, K., and Wang, H. (2015). The emerging neuroprotective role of mitochondrial uncoupling protein-2 in traumatic brain injury. Transl. Neurosci. 6, 179-186. doi: 10.1515/tnsci-2015-0019

Ock, J., Lee, H., Kim, S., Lee, W. H., Choi, D. K., Park, E. J., et al. (2006). Induction of microglial apoptosis by corticotropin-releasing hormone. J. Neurochem. 98 , 962-972. doi: 10.1111/j.1471-4159.2006.03933.x

Papadopoulou, N. G., Oleson, L., Kempuraj, D., Donelan, J., Cetrulo, C. L., and Theoharides, T. C. (2005). Regulation of corticotropin-releasing hormone receptor-2 expression in human cord blood-derived cultured mast cells. J. Mol. Endocrinol. 35, R1-R8. doi: 10.1677/jme.1.01833

Pardon, M. C. (2011). Therapeutic potential of some stress mediators in early Alzheimer's disease. Exp. Gerontol. 46, 170-173. doi: 10.1016/j.exger.2010. 09.006

Park, H. S., Park, M. J., and Kwon, M. S. (2016). Central nervous system-peripheral immune system dialogue in neurological disorders: possible application of neuroimmunology in urology. Int. Neurourol. J. 20, S8-S14. doi: 10.5213/inj. 1632614.307

Peixoto, P. M., Kim, H. J., Sider, B., Starkov, A., Horvath, T. L., and Manfredi, G. (2013). UCP2 overexpression worsens mitochondrial dysfunction and accelerates disease progression in a mouse model of amyotrophic lateral sclerosis. Mol. Cell. Neurosci. 57, 104-110. doi: 10.1016/j.mcn.2013. 10.002

Pennisi, M., Crupi, R., Di Paola, R., Ontario, M. L., Bella, R., Calabrese, E. J., et al. (2016). Inflammasomes, hormesis and antioxidants in neuroinflammation: role of NRLP3 in Alzheimer disease. J. Neurosci. Res. 95, 1360-1372. doi: 10.1002/jnr.23986

Perry, V. H. (2004). The influence of systemic inflammation on inflammation in the brain: implications for chronic neurodegenerative disease. Brain Behav. Immun. 18, 407-413. doi: 10.1016/j.bbi.2004. 01.004

Perry, V. H. (2010). Contribution of systemic inflammation to chronic neurodegeneration. Acta Neuropathol. 120, 277-286. doi: 10.1007/s00401-0100722-x

Perry, V. H. (2016). Microglia. Microbiol. Spectr. 4. doi: 10.1128/microbiolspec. MCHD-0003-2015

Perry, V. H., Cunningham, C., and Holmes, C. (2007). Systemic infections and inflammation affect chronic neurodegeneration. Nat. Rev. Immunol. 7, 161-167. doi: 10.1038/nri2015

Perry, V. H., Nicoll, J. A., and Holmes, C. (2010). Microglia in neurodegenerative disease. Nat. Rev. Neurol. 6, 193-201. doi: 10.1038/nrneurol.2010.17

Prinz, M., and Priller, J. (2017). The role of peripheral immune cells in the CNS in steady state and disease. Nat. Neurosci. 20, 136-144. doi: 10.1038/nn.4475

Qin, L., Wu, X., Block, M. L., Liu, Y., Breese, G. R., Hong, J. S., et al. (2007). Systemic LPS causes chronic neuroinflammation and progressive neurodegeneration. Glia 55, 453-462. doi: 10.1002/glia. 20467

Ramsden, D. B., Ho, P. W., Ho, J. W., Liu, H. F., So, D. H., Tse, H. M., et al. (2012). Human neuronal uncoupling proteins 4 and 5 (UCP4 and UCP5): structural properties, regulation and physiological role in protection against oxidative stress and mitochondrial dysfunction. Brain Behav. 2, 468-478. doi: 10.1002/brb3.55

Ransohoff, R. M., and Brown, M. A. (2012). Innate immunity in the central nervous system. J. Clin. Invest. 122, 1164-1171. doi: 10.1172/JCI58644

Ransohoff, R. M., Kivisäkk, P., and Kidd, G. (2003). Three or more routes for leukocyte migration into the central nervous system. Curr. Opin. Immunol. 3, 569-581. doi: 10.1038/nri1130

Ronnberg, E., Calounova, G., and Pejler, G. (2012). Mast cells express tyrosine hydroxylase and store dopamine in a serglycin-dependent manner. Biol. Chem. 393, 107-112. doi: 10.1515/BC-2011-220

Rousset, S., Emre, Y., Join-Lambert, O., Hurtaud, C., Ricquier, D., and CassardDoulcier, A. M. (2006). The uncoupling protein 2 modulates the cytokine balance in innate immunity. Cytokine 35, 135-142. doi: 10.1016/j.cyto.2006. 07.012 
Russi, A. E., Walker-Caulfield, M. E., and Brown, M. A. (2016). Mast cell inflammasome activity in the meninges regulates EAE disease severity. Clin. Immunol. doi: 10.1016/j.clim.2016.04.009 [Epub ahead of print].

Rustenhoven, J., Jansson, D., Smyth, L. C., and Dragunow, M. (2017). Brain pericytes as mediators of neuroinflammation. Trends Pharmacol. Sci. 38, 291-304. doi: 10.1016/j.tips.2016.12.001

Ryan, J. J., Morales, J. K., Falanga, Y. T., Fernando, J. F., and Macey, M. R. (2009). Mast cell regulation of the immune response. World Allergy Organ. J. 2, 224-232. doi: 10.1097/WOX.0b013e3181c2a95e

Ryu, J. W., Hong, K. H., Maeng, J. H., Kim, J. B., Ko, J., Park, J. Y., et al. (2004). Overexpression of uncoupling protein 2 in THP1 monocytes inhibits $\beta 2$ integrin-mediated firm adhesion and transendothelial migration. Arterioscler Thromb Vasc. Biol. 24, 864-870. doi: 10.1161/01.ATV.0000125705. 28058.eb

Saito, H. (2014). Mast cell research. Chem. Immunol. Allergy 100, 165-171. doi: $10.1159 / 000358733$

Saito, T., and Bunnett, N. W. (2005). Protease-activated receptors: regulation of neuronal function. Neuromolecular Med. 7, 79-99. doi: 10.1385/nmm:7:12:079

Sawikr, Y., Yarla, N. S., Peluso, I., Kamal, M. A., Aliev, G., and Bishayee, A. (2017). Neuroinflammation in Alzheimer's disease: the preventive and therapeutic potential of polyphenolic nutraceuticals. Adv. Protein Chem. Struct. Biol. 108, 33-57. doi: 10.1016/bs.apcsb.2017.02.001

Sayed, B. A., Walker, M. E., and Brown, M. A. (2011). Cutting edge: mast cells regulate disease severity in a relapsing-remitting model of multiple sclerosis. J. Immunol. 186, 3294-3298. doi: 10.4049/jimmunol. 1003574

Schain, M., and Kreisl, W. C. (2017). Neuroinflammation in neurodegenerative disorders-a review. Curr. Neurol. Neurosci. Rep. 17:25. doi: 10.1007/s11910017-0733-2

Schwartz, L. B. (2002). Mast cells and basophils. Clin. Allergy Immunol. 16, 3-42.

Secor, V. H., Secor, W. E., Gutekunst, C. A., and Brown, M. A. (2000). Mast cells are essential for early onset and severe disease in a murine model of multiple sclerosis. J. Exp. Med. 191, 813-822. doi: 10.1084/jem.191. 5.813

Segura-Aguilar, J., Paris, I., Muñoz, P., Ferrari, E., Zecca, L., and Zucca, F. A. (2014). Protective and toxic roles of dopamine in Parkinson's disease. J. Neurochem. 129, 898-915. doi: 10.1111/jnc.12686

Severini, C., Petrella, C., and Calissano, P. (2016). Substance P and Alzheimer's disease: emerging novel roles. Curr. Alzheimer Res. 13, 964-972. doi: 10.2174/1567205013666160401114039

Shaik-Dasthagirisaheb, Y. B., Varvara, G., Murmura, G., Saggini, A., Potalivo, G., Caraffa, A., et al. (2013). Vascular endothelial growth factor (VEGF), mast cells and inflammation. Int. J. Immunopathol. Pharmacol. 26, 327-335. doi: 10.1177/039463201302600206

Shalit, F., Sredni, B., Brodie, C., Kott, E., and Huberman, M. (1995). T lymphocyte subpopulations and activation markers correlate with severity of Alzheimer's disease. Clin. Immunol. Immunopathol. 75, 246-250. doi: 10.1006/clin.19 95.1078

Shi, M., Liu, C., Cook, T. J., Bullock, K. M., Zhao, Y., Ginghina, C., et al. (2014). Plasma exosomal $\alpha$-synuclein is likely CNS-derived and increased in Parkinson's disease. Acta Neuropathol. 128, 639-650. doi: 10.1007/s00401-0141314-y

Si, X., Pu, J., and Zhang, B. (2017). Structure, distribution, and genetic profile of $\alpha$-synuclein and their potential clinical application in Parkinson's disease. J. Mov. Disord. 10, 69-79. doi: 10.14802/jmd.16061

Silver, R., and Curley, J. P. (2013). Mast cells on the mind: new insights and opportunities. Trends Neurosci. 36, 513-521. doi: 10.1016/j.tins.2013.06.001

Silver, M. R., Margulis, A., Wood, N., Goldman, S. J., Kasaian, M., and Chaudhary, D. (2010). IL-33 synergizes with IgE-dependent and IgE-independent agents to promote mast cell and basophil activation. Inflamm. Res. 59, 207-218. doi: 10.1007/s00011-009-0088-5

Silverman, A. J., Sutherland, A. K., Wilhelm, M., and Silver, R. (2000). Mast cells migrate from blood to brain. J. Neurosci. 20, 401-408.

Sismanopoulos, N., Delivanis, D. A., Alysandratos, K. D., Angelidou, A., Therianou, A., Kalogeromitros, D., et al. (2012). Mast cells in allergic and inflammatory diseases. Curr. Pharm. Des. 18, 2261-2277. doi: $10.2174 / 138161212800165997$
Skaper, S. D. (2016). Mast cell - glia dialogue in chronic pain and neuropathic pain: blood-brain barrier implications. CNS Neurol. Disord. Drug Targets 15, 1072-1078. doi: 10.2174/1871527315666160829105533

Skaper, S. D., and Facci, L. (2012). Mast cell-glia axis in neuroinflammation and therapeutic potential of the anandamide congener palmitoylethanolamide. Philos. Trans. R. Soc. Lond. B Biol. Sci. 367, 3312-3325. doi: 10.1098/rstb.20 11.0391

Skaper, S. D., Facci, L., and Giusti, P. (2013). Glia and mast cells as targets for palmitoylethanolamide, an anti-inflammatory and neuroprotective lipid mediator. Mol. Neurobiol. 48, 340-352. doi: 10.1007/s12035-013-8487-6

Skaper, S. D., Facci, L., and Giusti, P. (2014). Mast cells, glia and neuroinflammation: partners in crime? Immunology 141, 314-327. doi: $10.1111 /$ imm. 12170

Skaper, S. D., Giusti, P., and Facci, L. (2012). Microglia and mast cells: two tracks on the road to neuroinflammation. FASEB J. 26, 3103-3117. doi: 10.1096/fj. 11-197194

Song, L., Pei, L., Yao, S., Wu, Y., and Shang, Y. (2017). NLRP3 inflammasome in neurological diseases, from functions to therapies. Front. Cell. Neurosci. 11:63. doi: $10.3389 /$ fncel.2017.00063

Stolmeier, D., Thangavel, R., Anantharam, P., Khan, M. M., Kempuraj, D., and Zaheer, A. (2013). Glia maturation factor expression in hippocampus of human Alzheimer's disease. Neurochem. Res. 38, 1580-1589. doi: 10.1007/s11064-0131059-3

Sui, Y. T., Bullock, K. M., Erickson, M. A., Zhang, J., and Banks, W. A. (2014). $\alpha$ synuclein is transported into and out of the brain by the blood-brain barrier. Peptides 62, 197-202. doi: 10.1016/j.peptides.2014.09.018

Sun, Y. X., Wang, J., Shelburne, C. E., Lopatin, D. E., Chinnaiyan, A. M., Rubin, M. A., et al. (2003). Expression of CXCR4 and CXCL12 (SDF-1) in human prostate cancers (PCa) in vivo. J. Cell. Biochem. 89, 462-473. doi: $10.1002 /$ jcb. 10522

Szekely, C. A., and Zandi, P. P. (2010). Non-steroidal anti-inflammatory drugs and Alzheimer's disease: the epidemiological evidence. CNS Neurol. Disord. Drug Targets 9, 132-139. doi: 10.2174/187152710791012026

Tagen, M., Elorza, A., Kempuraj, D., Boucher, W., Kepley, C. L., Shirihai, O. S., et al. (2009). Mitochondrial uncoupling protein 2 inhibits mast cell activation and reduces histamine content. J. Immunol. 183, 6313-6319. doi: 10.4049/jimmunol.0803422

Takeda, S., Sato, N., Ikimura, K., Nishino, H., Rakugi, H., and Morishita, R. (2013). Increased blood-brain barrier vulnerability to systemic inflammation in an Alzheimer disease mouse model. Neurobiol. Aging 34, 2064-2070. doi: 10.1016/j.neurobiolaging.2013.02.010

Takeda, S., Sato, N., and Morishita, R. (2014). Systemic inflammation, blood-brain barrier vulnerability and cognitive/non-cognitive symptoms in Alzheimer disease: relevance to pathogenesis and therapy. Front. Aging Neurosci. 6:171. doi: 10.3389/fnagi.2014.00171

Tanzola, M. B., Robbie-Ryan, M., Gutekunst, C. A., and Brown, M. A. (2003). Mast cells exert effects outside the central nervous system to influence experimental allergic encephalomyelitis disease course. J. Immunol. 171, 4385-4391. doi: 10.4049/jimmunol.171.8.4385

Taracanova, A., Alevizos, M., Karagkouni, A., Weng, Z., Norwitz, E., Conti, P., et al. (2017). SP and IL-33 together markedly enhance TNF synthesis and secretion from human mast cells mediated by the interaction of their receptors. Proc. Natl. Acad. Sci. U S A 114, E4002-E4009. doi: 10.1073/pnas.15248 45114

Teeling, J. L., and Perry, V. H. (2009). Systemic infection and inflammation in acute CNS injury and chronic neurodegeneration: underlying mechanisms. Neuroscience 158, 1062-1073. doi: 10.1016/j.neuroscience.2008 07.031

Tete, S., Tripodi, D., Rosati, M., Conti, F., Maccauro, G., Saggini, A., et al. (2012). Role of mast cells in innate and adaptive immunity. J. Biol. Regul. Homeost. Agents 26, 193-201.

Thangavel, R., Kempuraj, D., Zaheer, S., Raikwar, S., Ahmed, M. E., Selvakumar, G. P., et al. (2017). Glia maturation factor and mitochondrial uncoupling proteins 2 and 4 expression in the temporal cortex of Alzheimer's disease brain. Front. Aging Neurosci. 9:150. doi: 10.3389/fnagi.2017. 00150

Thangavel, R., Stolmeier, D., Yang, X., Anantharam, P., and Zaheer, A. (2012). Expression of glia maturation factor in neuropathological lesions of 
Alzheimer's disease. Neuropathol. Appl. Neurobiol. 38, 572-581. doi: 10.1111/j. 1365-2990.2011.01232.x

Theoharides, T. C., Alysandratos, K. D., Angelidou, A., Delivanis, D. A., Sismanopoulos, N., Zhang, B., et al. (2012). Mast cells and inflammation. Biochim. Biophys. Acta 1822, 21-33. doi: 10.1016/j.bbadis.2010. 12.014

Theoharides, T. C., Asadi, S., and Patel, A. B. (2013). Focal brain inflammation and autism. J. Neuroinflammation 10:46. doi: 10.1186/1742-20 94-10-46

Theoharides, T. C., Donelan, J. M., Papadopoulou, N., Cao, J., Kempuraj, D., and Conti, P. (2004). Mast cells as targets of corticotropin-releasing factor and related peptides. Trends Pharmacol. Sci. 25, 563-568. doi: 10.1016/j.tips.2004. 09.007

Theoharides, T. C., and Konstantinidou, A. D. (2007). Corticotropin-releasing hormone and the blood-brain-barrier. Front. Biosci. 12, 1615-1628. doi: $10.2741 / 2174$

Theoharides, T. C., Rozniecki, J. J., Sahagian, G., Jocobson, S., Kempuraj, D., Conti, P., et al. (2008). Impact of stress and mast cells on brain metastases. J. Neuroimmunol. 205, 1-7. doi: 10.1016/j.jneuroim.2008.09. 014

Theoharides, T. C., Stewart, J. M., Panagiotidou, S., and Melamed, I. (2016). Mast cells, brain inflammation and autism. Eur. J. Pharmacol. 778, 96-102. doi: 10.1016/j.ejphar.2015.03.086

Thornton, E., Tran, T. T., and Vink, R. (2010). A substance P mediated pathway contributes to 6-hydroxydopamine induced cell death. Neurosci. Lett. 481, 64-67. doi: 10.1016/j.neulet.2010.06.057

Thornton, E., and Vink, R. (2012). Treatment with a substance P receptor antagonist is neuroprotective in the intrastriatal 6-hydroxydopamine model of early Parkinson's disease. PLoS One 7:e34138. doi: 10.1371/journal.pone. 0034138

Tore, F., and Tuncel, N. (2009). Mast cells: target and source of neuropeptides. Curr. Pharm. Des. 15, 3433-3445. doi: 10.2174/138161209789105036

Tracey, K. J. (2009). Reflex control of immunity. Nat. Rev. Immunol. 9, 418-428. doi: $10.1038 /$ nri2566

Träger, U., and Tabrizi, S. J. (2013). Peripheral inflammation in neurodegeneration. J. Mol. Med. (Berl) 91, 673-681. doi: 10.1007/s00109013-1026-0

Tufekci, K. U., Meuwissen, R., Genc, S., and Genc, K. (2012). Inflammation in Parkinson's disease. Adv. Protein Chem. Struct. Biol. 88, 69-132. doi: 10.1016/B978-0-12-398314-5.00004-0

Utsuyama, M., Shiraishi, J., Takahashi, H., Kasai, M., and Hirokawa, K. (2003). Glia maturation factor produced by thymic epithelial cells plays a role in $\mathrm{T}$ cell differentiation in the thymic microenvironment. Int Immunol 15, 557-564. doi: $10.1093 /$ intimm/dxg056

Villarán, R. F., Espinosa-Oliva, A. M., Sarmiento, M., De Pablos, R. M., Arguelles, S., Delgado-Cortés, M. J., et al. (2010). Ulcerative colitis exacerbates lipopolysaccharide-induced damage to the nigral dopaminergic system: potential risk factor in Parkinson's disease. J. Neurochem. 114, 1687-1700. doi: 10.1111/j.1471-4159.2010. 06879.x

Visan, I. (2017). Neuroimmune interactions: astrocytes. Nat. Immunol. 18:254. doi: $10.1038 /$ ni.3700

Wang, Q., Chu, C. H., Qian, L., Chen, S. H., Wilson, B., Oyarzabal, E., et al. (2014). Substance P exacerbates dopaminergic neurodegeneration through neurokinin-1 receptor-independent activation of microglial NADPH oxidase. J. Neurosci. 34, 12490-12503. doi: 10.1523/jneurosci.2238-14.2014

Wang, Q., Oyarzabal, E., Wilson, B., Qian, L., and Hong, J. S. (2015). Substance $\mathrm{P}$ enhances microglial density in the substantia nigra through neurokinin-1 receptor/NADPH oxidase-mediated chemotaxis in mice. Clin. Sci. 129, 757-767. doi: $10.1042 / \operatorname{cs} 20150008$

Wang, T., Xiong, J. Q., Ren, X. B., and Sun, W. (2012). The role of Nogo-A in neuroregeneration: a review. Brain Res. Bull. 87, 499-503. doi: 10.1016/j. brainresbull.2012.02.011
Wilhelm, M., Silver, R., and Silverman, A. J. (2005). Central nervous system neurons acquire mast cell products via transgranulation. Eur. J. Neurosci. 22, 2238-2248. doi: 10.1111/j.1460-9568.2005.04429.x

Wu, Z., Zhang, J., and Zhao, B. (2009). Superoxide anion regulates the mitochondrial free $\mathrm{Ca}^{2+}$ through uncoupling proteins. Antioxid. Redox Signal. 11, 1805-1818. doi: 10.1089/ars.2009.2427

Wu, Z., Zhao, Y., and Zhao, B. (2010). Superoxide anion, uncoupling proteins and Alzheimer's disease. J. Clin. Biochem. Nutr. 46, 187-194. doi: 10.3164/jcbn. 09-104-2

Yehya, M., and Torbey, M. T. (2017). The role of mast cells in intracerebral hemorrhage. Neurocrit. Care doi: 10.1007/s12028-017-0416-5 [Epub ahead of print].

Zaheer, A., Fink, B. D., and Lim, R. (1993). Expression of glia maturation factor $\beta$ mRNA and protein in rat organs and cells. J. Neurochem. 60, 914-920. doi: 10.1111/j.1471-4159.1993.tb03237.x

Zaheer, A., Knight, S., Zaheer, A., Ahrens, M., Sahu, S. K., and Yang, B. (2008a). Glia maturation factor overexpression in neuroblastoma cells activates glycogen synthase kinase-3 $\beta$ and caspase-3. Brain Res. 1190, 206-214. doi: 10.1016/j.brainres.2007.11.011

Zaheer, A., Zaheer, S., Thangavel, R., Wu, Y., Sahu, S. K., and Yang, B. (2008b). Glia maturation factor modulates $\beta$-amyloid-induced glial activation, inflammatory cytokine/chemokine production and neuronal damage. Brain Res. 1208, 192-203. doi: 10.1016/j.brainres.2008.02.093

Zaheer, S., Thangavel, R., Sahu, S. K., and Zaheer, A. (2011). Augmented expression of glia maturation factor in Alzheimer's disease. Neuroscience 194, 227-233. doi: 10.1016/j.neuroscience.2011.07.069

Zaheer, A., Yorek, M. A., and Lim, R. (2001). Effects of glia maturation factor overexpression in primary astrocytes on MAP kinase activation, transcription factor activation and neurotrophin secretion. Neurochem. Res. 26 , 1293-1299.

Zaheer, A., Zaheer, S., Sahu, S. K., Knight, S., Khosravi, H., Mathur, S. N., et al. (2007). A novel role of glia maturation factor: induction of granulocytemacrophage colony-stimulating factor and pro-inflammatory cytokines. J. Neurochem. 101, 364-376. doi: 10.1111/j.1471-4159.2006.04385.x

Zhang, S., Dong, H., Zhang, X., Li, N., Sun, J., and Qian, Y. (2016). Cerebral mast cells contribute to postoperative cognitive dysfunction by promoting blood brain barrier disruption. Behav. Brain Res. 298, 158-166. doi: 10.1016/j.bbr. 2015.11.003

Zhang, S., Zeng, X., Yang, H., Hu, G., and He, S. (2012). Mast cell tryptase induces microglia activation via protease-activated receptor 2 signaling. Cell. Physiol. Biochem. 29, 931-940. doi: 10.1159/000171029

Zhou, Y., Lu, M., Du, R. H., Qiao, C., Jiang, C. Y., Zhang, K. Z., et al. (2016). MicroRNA-7 targets Nod-like receptor protein 3 inflammasome to modulate neuroinflammation in the pathogenesis of Parkinson's disease. Mol. Neurodegener. 11:28. doi: 10.1186/s13024-016-0094-3

Zhu, J., Qu, C., Lu, X., and Zhang, S. (2014). Activation of microglia by histamine and substance P. Cell. Physiol. Biochem. 34, 768-780. doi: 10.1159/0003 63041

Zou, K., Guo, W., Tang, G., Zheng, B., and Zheng, Z. (2013). A case of early onset Parkinson's disease after major stress. Neuropsychiatr. Dis. Treat. 9, 1067-1069. doi: $10.2147 /$ ndt.s48455

Conflict of Interest Statement: The authors declare that the research was conducted in the absence of any commercial or financial relationships that could be construed as a potential conflict of interest.

Copyright $\odot 2017$ Kempuraj, Thangavel, Selvakumar, Zaheer, Ahmed, Raikwar, Zahoor, Saeed, Natteru, Iyer and Zaheer. This is an open-access article distributed under the terms of the Creative Commons Attribution License (CC BY). The use, distribution or reproduction in other forums is permitted, provided the original author(s) or licensor are credited and that the original publication in this journal is cited, in accordance with accepted academic practice. No use, distribution or reproduction is permitted which does not comply with these terms. 